\title{
Acetyl-CoA the Key Factor for Survival or Death of Cholinergic Neurons in Course of Neurodegenerative Diseases
}

\author{
Andrzej Szutowicz • Hanna Bielarczyk • \\ Agnieszka Jankowska-Kulawy • Tadeusz Pawełczyk • \\ Anna Ronowska
}

Received: 23 March 2013/Revised: 19 April 2013/Accepted: 22 April 2013/Published online: 16 May 2013

(C) The Author(s) 2013. This article is published with open access at Springerlink.com

\begin{abstract}
Glucose-derived pyruvate is a principal source of acetyl-CoA in all brain cells, through pyruvate dehydogenase complex (PDHC) reaction. Cholinergic neurons like neurons of other transmitter systems and glial cells, utilize acetyl-CoA for energy production in mitochondria and diverse synthetic pathways in their extramitochondrial compartments. However, cholinergic neurons require additional amounts of acetyl-CoA for acetylcholine synthesis in their cytoplasmic compartment to maintain their transmitter functions. Characteristic feature of several neurodegenerating diseases including Alzheimer's disease and thiamine diphosphate deficiency encephalopathy is the decrease of PDHC activity correlating with cholinergic deficits and losses of cognitive functions. Such conditions generate acetyl-CoA deficits that are deeper in cholinergic neurons than in noncholinergic neuronal and glial cells, due to its additional consumption in the transmitter synthesis. Therefore, any neuropathologic conditions are likely to be more harmful for the cholinergic neurons than for noncholinergic ones. For this reason attempts preserving proper supply of acetyl-CoA in the diseased brain, should attenuate high susceptibility of cholinergic neurons to diverse neurodegenerative conditions. This review describes how common neurodegenerative signals could induce deficts in cholinergic neurotransmission through
\end{abstract}

\footnotetext{
A. Szutowicz $(\bowtie) \cdot$ H. Bielarczyk · A. Jankowska-Kulawy ·

A. Ronowska

Department of Laboratory Medicine, Medical University of Gdańsk, Ul. Dębinki 7, 80-211 Gdańsk, Poland

e-mail: aszut@gumed.edu.pl

T. Pawełczyk

Department of Molecular Medicine, Medical University of Gdańsk, Gdańsk, Poland
}

suppression of acetyl-CoA metabolism in the cholinergic neurons.

Keywords Acetyl-CoA · Alzheimer's disease · Cholinergic neurons · Neurotoxins · Pyruvate dehydrogenase $\cdot$ Thiamine deficiency

\section{General Outline of Brain Energy Metabolism}

Brain constitutes for $2 \%$ of human body mass but under resting conditions it utilizes $20 \%$ of whole body oxygen and glucose. Glucose is transported across the blood brain barrier through insulin independent, low-affinity highcapacity, glucose down regulated Glut 1 transporter. Due to the high rate of glucose utilization by brain cells its concentration in CSF is equal to two/third of its level in general circulation. Glucose is an almost exclusive energy substrate in the brain that through glycolytic pathway yields pyruvate, a key precursor of acetyl-CoA, which feeds TCA cycle. The latter is synthesized almost exclusively by pyruvate dehydrogenase complex (pyruvate: lipoate oxidoreductase acceptor acetylating, PDHC) that activities in whole brain, as well as in isolated brain mitochondria are 4-10 times higher than in respective fractions of non excitable tissues. The highest activity of PDHC was found in the hippocampus and the lowest one (60\% lower) in the medulla oblongata [1, 2]. These PDHC patterns did not correlate with differential regional distribution of ChAT activities [2, 3]. It might result form the fact that cholinergic neurons form small about $1 \%$ fractions of entire brain cell population. Therefore, particular interactions between energy and cholinergic metabolism ought to be investigated using models containing greater density of cholinergic neurons. 


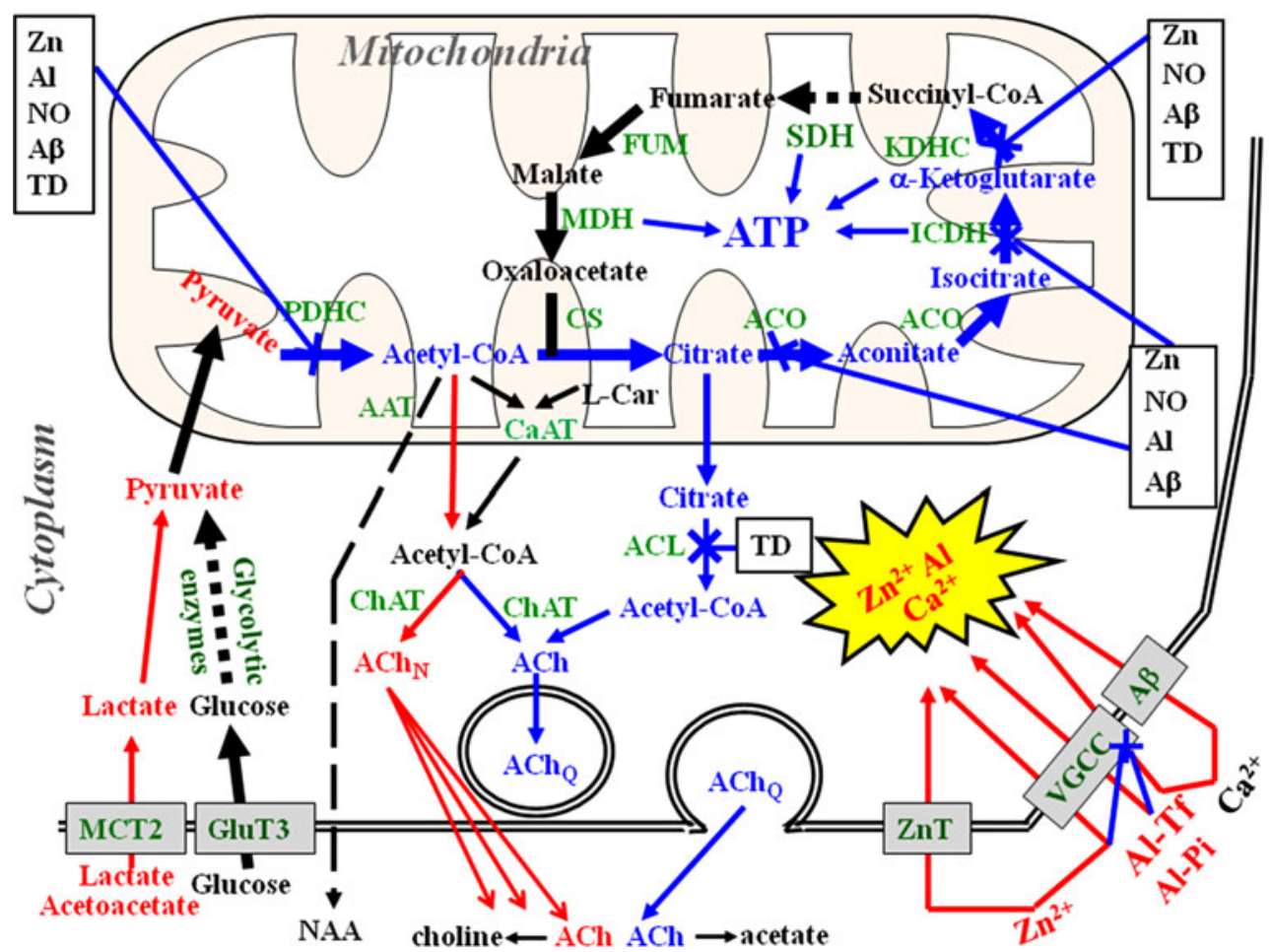

Fig. 1 Pathways of acetyl-CoA and energy metabolism in cholinergic neurons of neurodegenerating brain. Combination of diverse neurotoxic signals contributes to Alzheimer's and other types of cholinergic encephalopathies. They inhibit PDHC and acetyl-CoA synthesis yielding energy deficits of entire population of brain cells. However, cholinergic neurons are more susceptible than others to these neurodegenerative inputs. Cytotoxic-signal induced excessive depolarization of glutaminergic terminals causes increase of $[\mathrm{Zn}]$ and [Glu] in the synaptic cleft. Zn, Ca, and chronically accumulated Al enter depolarized postsynaptic cholinergic neurons through $\mathrm{ZnTs}$, VGCC, NMDA and/or A $\beta$ high permeability channels. The increase of cytoplasmic $\left[\mathrm{Ca}^{2+}\right]$ activates nNOS, whereas subsequent everload of mitochondria with this cation inhibits PDHC. Also $\mathrm{Zn}$ or NOderived peroxynitrite radicals acutely inhibit PDHC and other other enzymes of TCA cycle yielding depression of acetyl-CoA synthesis and its utilization for ATP production in the mitochondria. Chronic accumulation of $A \beta$ in extra and intracellular compartments, alone or

Neurons that constitute about $10 \%$, of brain cells consume $70 \%$ of glucose and oxygen supplied to this organ. That is due to the fact that neurons, possess high density/ high glucose affinity Glut 3 transporters and their in situ, rates of metabolic fluxes of high-energy intermediates that are at least 20 times faster than in glial cells (Fig. 1) [4]. Brain may also utilize acetoaetate/ $\beta$-hydroxybytyrate as a complementary source of acetyl-CoA [5, 6]. In physiological conditions levels of these ketoacids in extracellular fluids are well below $0.05 \mathrm{mmol} / \mathrm{L}$. However, under pathologic conditions, such as diabetes, their extracellular concentrations may reach levels as high as $5 \mathrm{mmol} / \mathrm{L}$. At such concentrations, ketoacids enter the brain through MCTs competing effectively with lactate (Fig. 1). Under in vitro conditions, these ketoacids were capable in combination with $\mathrm{Ca}$ and other metals alters multiple transport entities in the plasma and mitochondrial membranes and directly inhibits PDHC and aconitase. The prolonged depolarization and energy deficts increase nonquantal $\mathrm{ACh}$ release and inhibit its quantal Ca-dependent release. These conditions limit direct or ACL-dependent transport acetyl-CoA from mitochondria to the site of ACh synthesis in the synaptoplasmic compartment. The decrease of acetyl$\mathrm{CoA}$ in the synaptoplasm causes instant inhibition of ChAT, yielding depression of $\mathrm{ACh}$ pool and rates of its quantal release. Prolonged decrease of cytoplamic [acetyl-CoA] results in adaptative suppression of ChAT expression aggravating deficits of cholinergic neurotransmission. Part of acetyl-CoA pool is utilized for intramitochondrial NAA synthesis, which is subsequently released out of the neuron. Decrease of mitochondrial acetyl-CoA results in energy deficits, and correlates with death rate of cholinergic neurons. Red arrows activation, blue arrows inhibition, green letters enzymes, black boxes neurotoxic agents (Color figure online)

maintaining normal levels of ATP and phosphocreatine in different brain preparations. Moreover, in diabetic-ketotic rat brain ketoacids along with glucose or pyruvate caused marked rises acetyl-CoA, ACh synthesis and release from isolated nerve terminals [7].

Under in vitro conditions, neuronal cells utilize lactate/ pyruvate as preferred energy substrates. The increase of lactate in circulation during exercise or pathologic hypoxia may cause several fold increase of its transport through the BBB. Inside the cells lactate remains in equilibrium with pyruvate due to very high activity of lactic dehydrogenase. Therefore, the net rate of its flux to pyruvate depends on utilization rate of the latter in PDHC and pyruvate carboxylase reactions. Pyruvate through PDHC reaction is almost exclusive source of acetyl-CoA in neurons and 
Fig. 2 Selected correlations between different parameters of energy and $\mathrm{ACh}$ metabolism in differentiated SN56 cholinergic neuronal cells and brain nerve terminals under various neurotoxic and neuroprotective conditions (a-d): a significant correlation between cell viability and PDHC activity; b significant correlation between cell viability and acetyl-CoA level in their mitochondria; c significant correlation between cytoplasmic acetyl-CoA level and ChAT activity; $\mathbf{d}$ significant correlation between ACh synthesis and cytoplasmic acetyl-CoA level; e significant correlation between PDHC and ChAT activities in differentiated cholinergic cells and lack of such correlation in nondifferentiated ones; f significant inverse correlations between ChAT activities (circles)/ACh contents (triangles) and whole cell acetyl-CoA levels in different genetically and postranslationally modified phenotypes of cholinergic SN56 cells. (1) Native differentiated (DC) and nondifferentiated (NC) SN56 cells; (2) TrkA expressing T17 NC/DC SN56 cells; 3. 2ChAT overexpressing NC/DC SN56 cells. Data recalculated from: [27, 35-38, $45,54-56,79,131]$
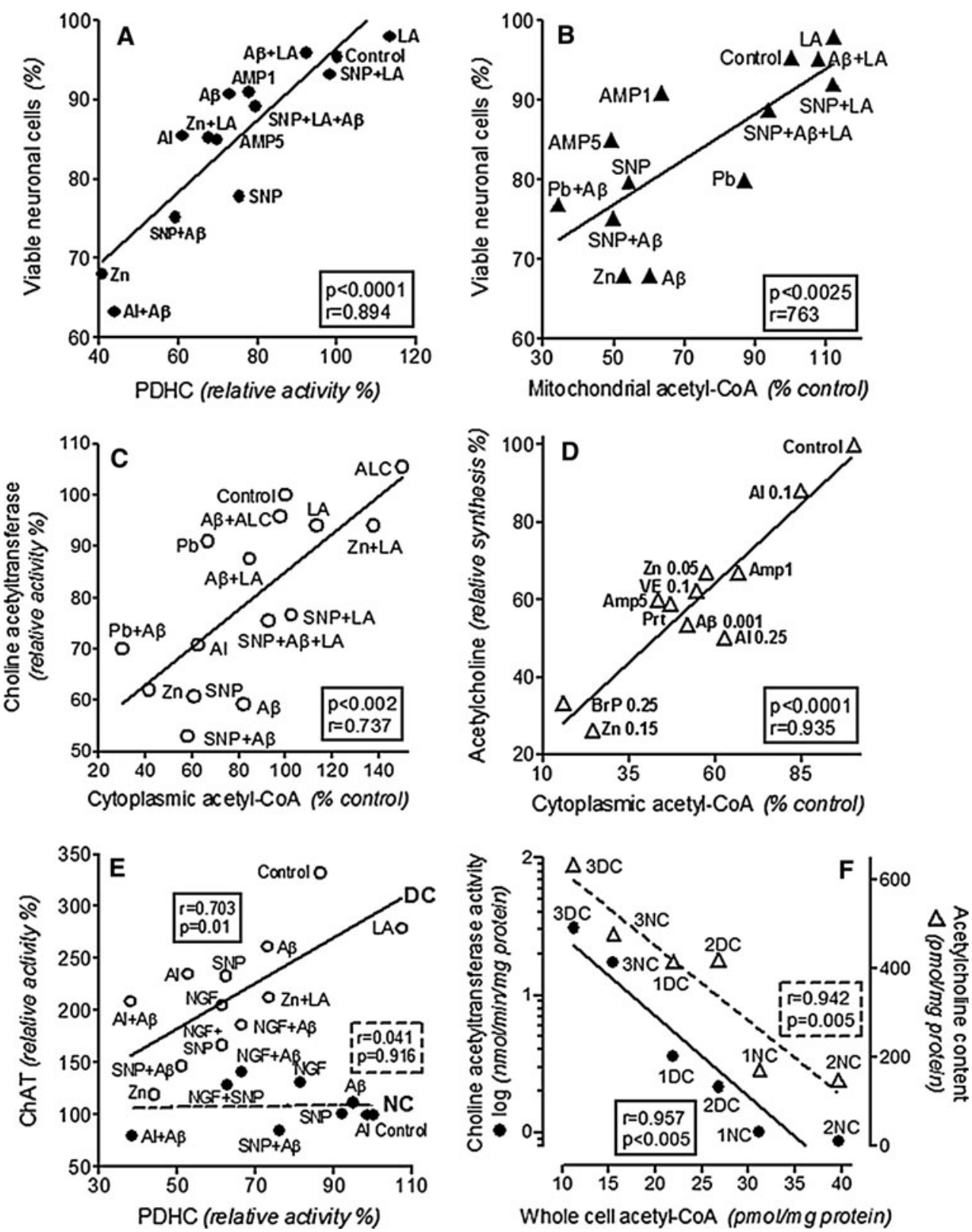

other types of brain cells (Fig. 1). However, anaplerotic reaction of pyruvate carboxylation to oxaloacetate by pyruvate carboxylase occurs mainly in astrocytes [8]. Therefore, oxaloacetate has to be transported into the neurons through indirect oxaloacetate-aspartate and glutamine-glutamate shunts. Both metabolites are required by citrate synthase to feed TCA cycle.

Also astrocytes produce large amounts of lactate. Fraction of this metabolite is taken up and utilized by the neurons thanks to high expression of MCT in the neuronal plasma membranes, and PDHC activity in their mitochondria [9]. Therefore, the astrocyte-derived lactate is postulated to be an important precursor of acetyl-CoA and oxaloacetate-substrates for condensation reaction and energy production in neurons. Results of in vitro experiments on brain slices, synaptosomes and cultured neuronal cells demonstrate that lactate/pyruvate with L-malate are better energy substrates and precursors of acetyl moiety for ACh synthesis than glucose [10].

On the contrary, under in vivo conditions blood lactate, even in high concentrations, could not fully replace the glucose, despite of robust expression of MCT on the blood brain barrier. Only during the suckling period brain is capable to extract lactate from circulation [11]. The source of discrepancies between in vivo and in vitro experiments remains unknown. 
Neurons have no capacity for acetate utilization. However, they synthesize large amounts of $\mathrm{N}$-acetyl- $\mathrm{N}$-aspartate (NAA) in aspartate-CoA transferase (acetyl-CoA:L-aspartate $N$-acetyltransferase, EC 2.3.1.17) reaction located in their mitochondria. Neurons contain $98.7 \%$ fraction of overall brain pool of this metabolite (Fig. 1). Its intraneuronal concentration reaches levels $20 \mathrm{mmol} / \mathrm{L}$ [12]. NAA is transported to oligodendrocytes, where it may be hydrolysed to acetate by aspartoylacylase (aminohydrolase II, EC 3.5.1.15) and converted back to acetyl-CoA by acetylCoA synthetase (acetate:CoA ligase AMP, EC 6.2.1.1).

Overall NNA concentration in the brain is in the range of $10 \mathrm{mmol} / \mathrm{kg}$. Therefore, its signal in the brain can be easily detected by PET and used as marker of viability of brain neurons. The levels of NAA were found to be decreased in the specific regions of cerebral cortex in various brain pathologies including: Alzheimer's, Parkinson's diseases as well as Wernicke, dialysis and aluminum encephalopathies [12]. In each of these pathologies the PDHC activity and parameters of energy metabolism were found to be decreased. Experiments on animal and cellular models of these encephalopathies demonstrated inhibition of PDHC that correlated with suppression of acetyl-CoA levels in the mitochondrial compartment and the rate of cell death (Figs. 1, 2) [1, 6, 13-15]. It might directly decrease the rate of NAA synthesis in the aspartate acetyltransferase reaction. However, no direct correlation studies are available.

Oral administration of large doses of glyceride triacetate was reported to cause marked increases of acetyl-CoA and phosphocreatine levels in the rat brain [16]. This rise was linked with attenuation LPS-induced inflammatory reactions in microglia and improvement of energy metabolism in glial cells $[16,17]$.

Total number of astrocytic, microglial and oligodendroglial cells in the brain is 10 times greater than that of the neurons, but their oxidative metabolism utilizes only $30 \%$ of the brain glucose. They display about 4 times lower activities of PDHC, ketoglutarate dehydrogenase (2-oxoglutarate:lipoate oxidoreductase acceptor acylating, EC 1.2.4.2., KDHC) and other enzymes of oxidative metabolism than neurons $[18,19]$. High level of phosphorylation of E1 subunit of PDHC in astrocytes, could also inhibit pyruvate consumption in this compartment [20]. On the contrary, in astrocytes rates of glucose and lactate uptake are 2-4 times faster than in isolated neurons. Therefore, astrocytes may release both lactate and glucose to support neuronal energy metabolism [21, 22]. Accordingly, oxidative metabolism in neurons, but not in astroglia, was strongly activated by pyruvate and lactate. It gives rise to the hypothesis that under hypoxic/hypoglycemic conditions lactate may replace glucose as a principal energy substrate $[21,23]$.
Astrocytes also avidly take up glutamate, released from glutamatergic terminals, through EAAT1-2 transporters and convert it to L-glutamine in Pi-activated glutamine synthetase reaction [24]. Thereby, they protect postsynaptic neurons against excitotoxic injury, by excess of extracellular L-glutamate. In addition, astrocytes contain high activities of pyruvate carboxylase yielding production large amounts of oxaloacetate [8]. They supply these metabolites to the neurons in form of glutamine and aspartate, through glutamine-glutamate and aspartate shuttles, respectively [8]. Most of compartmentalization studies were performed on isolated primary neuronal or glial cell cultures, to deal with possibly homogenous cellular populations [24]. One should, however keep in mind that these cultures are still heterogeneous. For instance, primary neuronal cultures consist of neurons of different transmitter systems with dominating fraction of glutamatergic ones.

However, activities of PDHC in different brain regions displayed no correlations with distribution specific markers of cholinergic pericarya and/or terminals [2, 3, 25]. Also, differentiation of SN56 cholinergic cells was accompanied by the decrease but not increase of PDHC activity [26, 27]. It indicates that rate of acetyl-CoA synthesis by PDHC in cholinergic neurons is not positively linked with expression their transmitter phenotype (Fig. 1). On the other hand, during postnatal development the increase of ChAT activity in cerebrum was accompanied by respective elevations in PDHC levels, what might be compatible with maturation-induced activation all transmitter systems [3, 28, 29].

\section{Age Dependent Modifications}

Brain maturation stimulates glucose uptake, glycolysis and oxidative pathways due to increased expression of respective genes and enzyme levels. These alterations display temporal correlations with maturation-dependent elevations in brain cholinergic and glutamatergic transmitter metabolism, both requiring an adequate provision of acetyl-CoA by PDHC and its flux through TCA [28, 30, 31]. On the other hand, physiologic brain aging is characterized by continuous, although relatively small, decline of structural and metabolic markers of cholinergic neurons and their key physiological neurotransmitter functions. Also, no alterations in activities of key enzymes of oxidative metabolism including PDHC, KDHC, aconitase and other enzymes of TCA cycle and respiratory chain were found [25]. However, in these conditions deficits in several antioxidative species such as glutathione, carnitine and lipoate along with excessive glutamatergic signaling, and free radical production appeared [32-34]. That, made aged brains increasingly vulnerable to common pathologic conditions such as hypoxia, hypoglycemia, excitotoxic 
stimulation, amyloid- $\beta$ accumulation, $\mathrm{Zn}, \mathrm{Fe}, \mathrm{Al}$ excess and thiamine (TD) or other vitamin deficiences (Fig. 1). All these pathologic signals strongly inhibited PDHC, KDHC, aconitase [citrate (isocitrate)hydrolase, EC 4.2.1.3.] and other key enzymes of acetyl-CoA and energy metabolism (Fig. 1) [14, 27, 35-38]. It might cause fast decay of cholinergic neurons located in the septal nuclei (Fig. 2a, b), thereby aggravating age-dependent physiologic limitations of memory and cognitive functions [39]. In addition, other studies on 24 months rats revealed marked $40 \%$ decrease of PDHC activity, with concomitant increases in expression and activity of pyruvate dehydrogenase kinase (ATP:[pyruvate dehydrogenase (acetyltransferring)] phosphotransferase, EC 2.7.11.2.), yielding hiperphosphorylation of PDHC-E1 subunit. That, could be responsible for decreased levels of ATP and increased accumulation of lactate in senescent brains [40].

\section{Key Role of Acetyl-CoA}

Acetyl-CoA is a key energy precursor-intermediate in all cells of our organism. In the brain it is almost exclusively synthesized in the mitochondria in PDHC reaction providing $97 \%$ of energy (Fig. 1). Brain does not utilize fatty acids as a source of acetyl-CoA. However, during systemic ketosis it may utilize $\beta$-hydroxybutyrate-derived acetoacetate through acetoacetyl-CoA synthestase, succinyl-CoA acyltransferase, and acetoacetyl-CoA thiolase reactions. Irrespective of the origin, acetyl-CoA is efficiently incorporated into TCA cycle through high activity citrate synthase step. Its equilibrium constants equal to $2.2 \times 10^{8}$ shifts this reaction far toward citrate formation [41]. It causes the level of acetyl-CoA in brain mitochondria being low and strongly dependent on the rate of its synthesis by PDHC (Fig. 1). Therefore, any conditions suppressing PDHC activity decrease acetyl-CoA level in the brain mitochondria. Significant correlations between PDHC activity and acetyl-CoA levels have been reported in our studies on different models of neurodegeneration (Fig. 2a, b) $[6,12,42-44]$.

In last 40 years number of studies directly assessed acetyl-CoA content in different brain preparations [7, 43, 45-55]. However, majority of them did not take into account apparent differences in acetyl-CoA distribution between mitochondrial and cytoplasmic compartments in cholinergic and noncholinergic neurons as well as in glial cells. Only experiments performed either on brain nerve terminals or in clonal cholinergic neuronal SN56 cell lines assessed subcellular distribution of acetyl-CoA, so far [14, 36, 38, 45, 56]. These models enabled one to investigate acetyl-CoA shifts between mitochondrial and cytoplasmic compartment in pure cholinergic cells under different physiologic and pathogenic conditions (Figs. 1, 2).
Small fraction of mitochondrial acetyl-CoA, not used in TCA cycle, serves as a source of acetyl units for different synthetic processes taking place in cytoplasmic compartment of these neuronal cells (Fig. 1). However, in resting neurons inner mitochondrial membrane is relatively impermeable for acetyl-CoA and other acyl-CoA esters $[6,57]$. Therefore, acetyl units are transported to cytoplasm indirectly, in the form of citrate, acetyl-L-carnitine, or acetate (Fig. 1) [57]. Citrate leaves mitochondria through dicarboxylate transporter to be cleaved by ATPcitrate lyase (acetyl-CoA:oxaloacetate $C$-acetyltransferase [(pro-S)carboxymethyl-forming, ADP phosphorylating, EC 2.3.3.8, ACL) to acetyl-CoA and oxaloacetate. Studies with specific inhibitor of ACL (-) hydroxycitrate revealed that this pathway provides about $30-50 \%$ of acetyl units in the cytoplasmic compartment of both neuronal and glial cells $[44,45,58]$. On the other hand, carnitine acetyl transferase system (acetyl-CoA:carnitine $O$-acetyltransferase, EC 2.3.1.7) in the brain mitochondria was found to be active only in the presence of excess of exogenous acetyl-L-carnitine (ALC) [59, 60]. Also immature brains were reported to take up and metabolize ALC from the blood more avidly than the adult ones [61].

Studies on whole brain mitochondria of mixed glialneuronal origin have demonstrated that pathophysiologically relevant $\left[\mathrm{Ca}^{2+}\right]$ of $10^{-6} \mathrm{~mol} / \mathrm{L}$ concentrations, evoked direct release of acetyl-CoA (Fig. 1) [14, 45, 50]. Also in synaptosomes adequate fraction of their mitochondrial acetyl-CoA was found to reach cytoplasm directly through Ca-activated, verapamil-inhibited pathway (Fig. 1) [45, 56]. In primary neurons depolarization increased cytoplasmic $\left[\mathrm{Ca}^{2+}\right]$, and opened reversible, high permeability transition anionic channels (PTP) through which acetylCoA moieties might diffuse from mitochondria to cytoplasm, down the concentration gradient [36, 62].

In addition, acetyl-CoA may leave mitochondria as NAA. [12]. Concentrations of substrates for aspartate $\mathrm{N}$-acetyltransferase, aspartate and acetyl-CoA, are estimated to be about 1.0 and $0.12 \mathrm{mmol} / \mathrm{L}$ [36], whereas corresponding $\mathrm{Km}$ values are equal to 0.58 and $0.058 \mathrm{mmol} / \mathrm{L}$, respectively [36, 63]. Therefore, pathologies that depress acetyl-CoA formation by PDHC in the brain are likely to decrease its NAA levels. Indeed, the loss of NAA was observed in brain PET scans of AD and PD patients [13, 64]. Neurons cannot utilize NAA as a source of acetate as they contain no aspartoylhydrolase in their cytoplasm. Therefore, NAA may serve as an acetyl moiety donor after its release to extracellular space followed by its uptake by oligodendroglia. The metabolic flux of acetyl units through this pathway was estimated to be equal to $2.5-3.0 \%$ of rates of glucose to pyruvate and $1.2 \%$ pyruvate to acetyl-CoA conversion rates, respectively $[12,36]$. 
These data indicate that there is an intra and intercellular compartmentalization of acetyl-CoA in the brain. Acetyl$\mathrm{CoA}$ in each cellular compartment of the brain forms two metabolically linked but functionally independent pools (Fig. 1). Brain mitochondria are the primary compartment for acetyl-CoA synthesis by the PDHC. Over $90 \%$ of acetyl-CoA is subsequently utilized for energy production. Thus, availability of this metabolite in mitochondria may be a key factor determining viability of neuronal and other cell types in brain (Figs. 1, 2b) [27]. Concentration of acetyl-CoA in the mitochondrial matrix is 5-7 times higher than in cytoplasm and might determine rates of its transport to latter compartment [36]. On the other hand, the influence of cytoplasmic acetyl-CoA itself on velocity of different synthetic pathways seems to be independent of the mitochondrial pool (Fig. 2e) [38, 65].

\section{Age-Dependent Alterations of Brain Acetylcholine Metabolism}

\section{Cholinergic Transmission}

The cholinergic transmission is performed by specific groups of neurons, which synthesize ACh in cytoplasmic compartment, accumulate in synaptic vesicles and release it into the synaptic cleft in a quantal, Ca-dependent mode. Neurotransmitter binding with subsequent activation of postsynaptic muscarinic and nicotinic receptors is connected with cognitive functions, emotional reactions as well as short and long term memory formation in humans and animals.

ACh is synthesized by choline acetyltransferase (acetylCoA:choline $O$-acetyltransferase, EC 2.3.1.6., ChAT) from acetyl-CoA and choline in cytoplasmic compartment of cholinergic neuron axonal terminals which equilibrium constant equal to 13 favors formation of this transmitter:

choline + acetyl-CoA $\rightleftarrows \mathrm{ACh}+\mathrm{CoA}$

The release of ACh creates out of equilibrium conditions in transmitter synthesizing compartment and triggers ChAT reaction. There is thought, that transmitter functions are executed by ACh synthesized in cholinergic nerve terminals and accumulated in synaptic vesicles and released in a quantal mode in response to their depolarization. The content of $\mathrm{ACh}$ in cholinergic neurons is maintained on quite stable level despite of marked variations in their activity $[6,66]$. It indicates that ChAT activity in cholinergic neurons in situ is high enough to prevent ACh depletion during their activity. Levels of acetyl-CoA and choline in cytoplasm of cholinergic neurons were found to be much below their optimal concentrations used in assay media $[6,66]$. Therefore, the rate of ACh synthesis under out of equilibrium conditions, induced by the evoked transmitter release, may be regulated by both ChAT protein level, as well as by substrates availability.

Both ChAT and VAChT are recognized specific structural markers for cholinergic neurons. Their levels depend on the expression of CHAT and VACHT genes sharing common cholinergic locus regulated by promoters, activated by CREB and retinoic acid receptors (RAR) [67]. Also nerve growth factor (NGF) was found to induce differentiation of septal cholinergic neurons through multiple signaling pathways linked with TrkA, high affinity surface receptors and suppressed through low specificity p75 receptors [27, 54, 55, 68]. Activation of these pathways leads to increased expression of ChAT, VAChT, high affinity choline transport system (CHT1) yielding morphologic maturation and activation of ACh metabolism [54, 69, 70].

Both in ageing animals and in humans decrease in cortical ACh metabolism precedes those in ChAT and VAChT expression [6, 71-73]. In rats, loses in these cholinergic markers, as well as decreased density of cholinergic neurons in the septum, and progressive cognitive deficits appeared several months later. However, in senescence-accelerated, 8th and 12th month old mice, loses in activity and mRNA for ChAT in hippocampus and cerebral cortex as well as decreases in density of septal cholinergic neurons significantly correlated with deterioration their spatial cognitive tests [74]. There are suggestions that age-linked neurodegeneration may be caused by disequilibrium between TrkA and p75NTR receptors [75].

\section{Metabolism of Acetyl Moiety of Acetylcholine}

There is little data on regulation of acetyl-CoA metabolism in brain cholinergic neurons. It results from the fact that cholinergic neurons constitute about 1 and $10 \%$ of whole brain cell and nerve terminal populations, respectively [76]. Therefore, any conclusion concerning pathologic alterations in acetyl-CoA metabolism in cholinergic neurons, are drawn with assumption, that changes of this metabolite in cholinergic and noncholinergic compartments remain the same. However, that may not be the case. For instance, clonal SN56 cholinergic cells from mice septum, with low and high expression of the cholinergic phenotype, had higher and lower levels of acetylCoA in their mitochondria, respectively (Fig. 2f) (Table 1) [38, 54, 77].

Acetyl-CoA for synthesis of transmitter pool of ACh is synthesized almost exclusively inside of cholinergic neuron mitochondria by PDHC from glucose-derived pyruvate (Fig. 1). In ketotic diabetes part acetyl units for $\mathrm{ACh}$ synthesis may be provided by acetoacetate/ $\beta$ - 


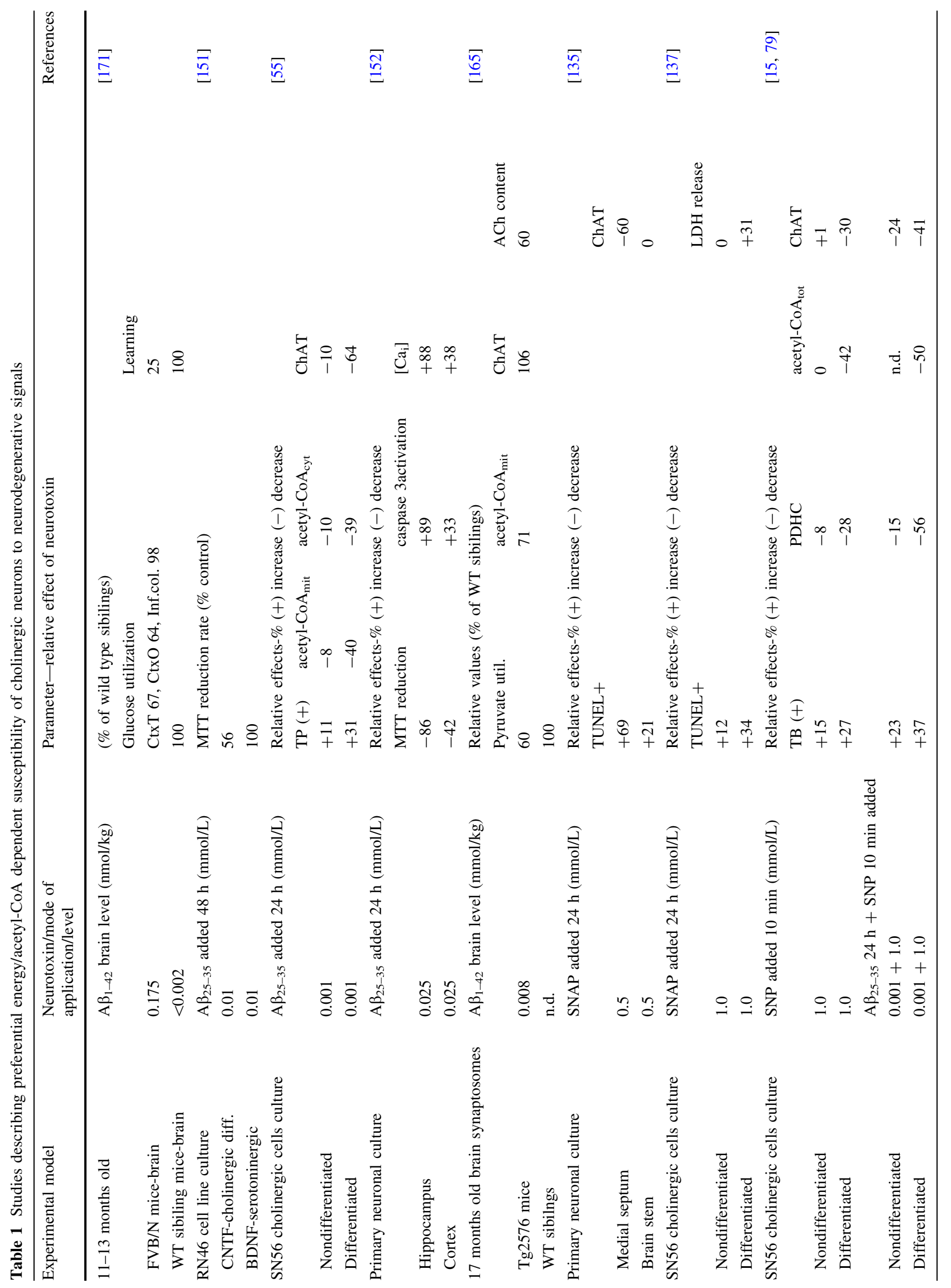




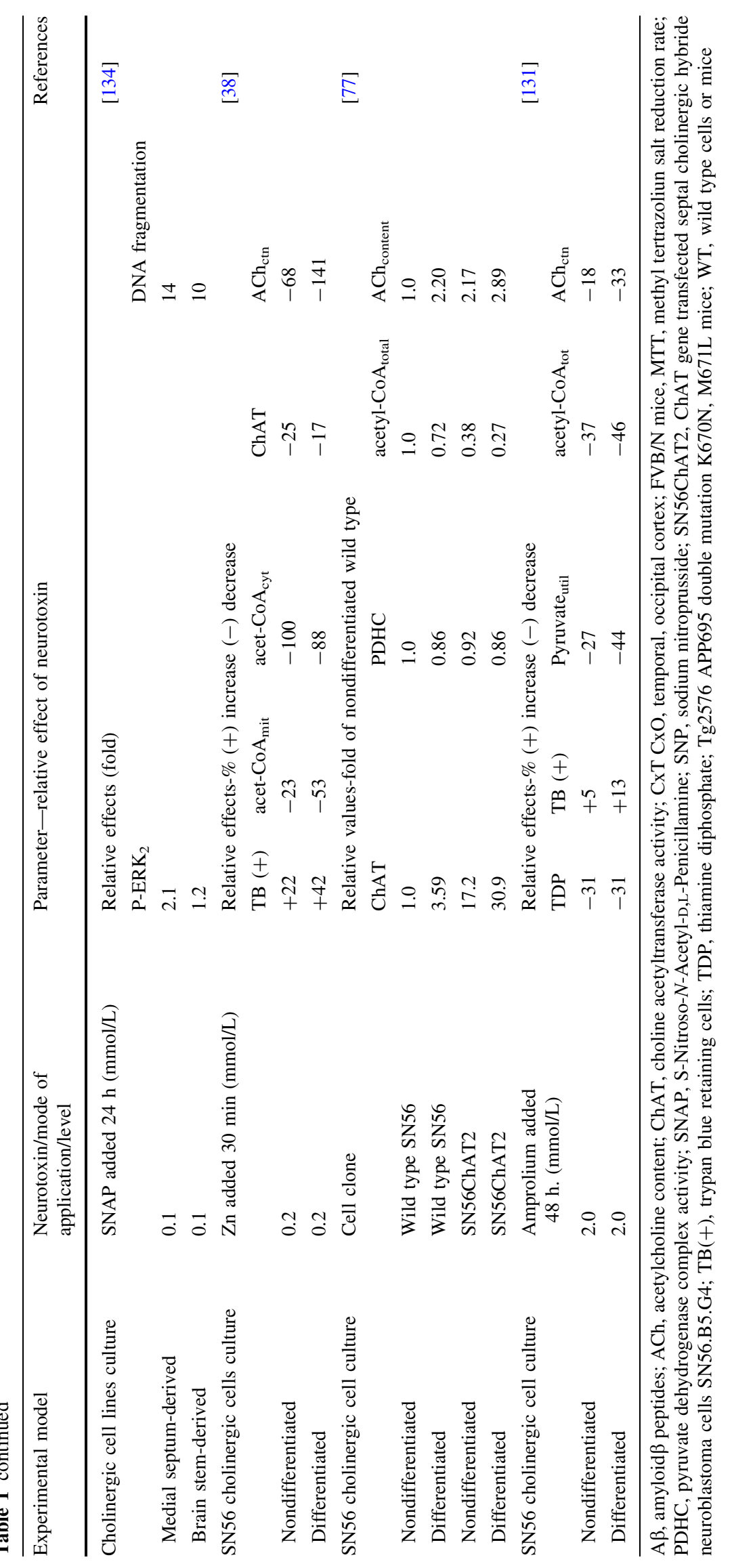


hydroxybutyrate $[5,7]$. It is estimated, that only $1-3 \%$ of acetyl-CoA pool synthesized in cholinergic neurons is utilized for ACh production. Despite of that there is a tight interdependence between pyruvate oxidation and $\mathrm{ACh}$ content and rate of release both in whole brain, isolated synaptosomes as well as in cultured cells $[15,35,78,79]$. That may be due to the competition for acetyl-CoA between high velocity TCA and relatively slow rate transporting pathways (Fig. 1) (Table 1).

Among several pathways of acetyl group transfer through the mitochondrial membrane (see "Key Role of Acetyl-CoA") only two seem to be significant sources of acetyl-CoA for ACh synthesis in the cholinergic neurons. They are: ACL pathway, providing $20-50 \%$ of acetyl units, and the direct efflux of acetyl-CoA through Cadependent reversible PTP (Fig. 1) [44, 45, 50].

In addition, ACL pathway provides acetyl-CoA for acetylation of histones and different structural proteins of various mammalian cells including neurons [65]. Thereby, acetyl-CoA-dependent disturbances in protein acetylation may contribute to epigenetic pathomechanisms of Alzheimer's and other neurodegenerative diseases [80, 81].

During postnatal development of cerebrum activity of ChAT increased several-fold, but the ACL activity remained on stably high level. On the other hand, in cerebellum containing no cholinergic elements, activity of ACL was decreased by about $70 \%[3,31]$. Significant correlations have been found between ChAT and ACL activities in different regions of the brain, and in lesioned hippocampus [82]. Also, differentiation of cholinergic S-20 but not NIE-115 dopaminergic neuronal cells caused twofold increase of ACL activity [83].

There is generally accepted that in resting cells in situ, mitochondrial inner membrane is impermeable to acetylCoA [45, 57]. However, depolarization-induced increase of cytoplasmic $\mathrm{Ca}^{2+}$ may generate reversible PTP, allowing transient direct release of acetyl-CoA from mitochondria to cytoplasm [45, 62, 84]. Studies with $\mathrm{Ca}$ chelators and Ca-channel antagonists indicate that up to $60-70 \%$ of acetyl-CoA for ACh synthesis is transported out of mitochondria by the direct release [56].

ALC is thought to be another alternative source of acetyl units for brain ACh synthesis. Under in vivo conditions systemic application of ALC was found to improve energy and ACh metabolism in the brain, as well as cognitive performance of aged or pharmacologically depressed animals $[60,85,86]$. In fact, dietary supplementation of mice with ALC attenuated pentylenetetrazole-induced seizures through restoration normal levels of ATP and NAA [87]. Beneficial effects of ALC supplementation might result from general improvement of energy metabolism and synthesis of structural lipids but not from specific influence on neurotransmission in cholinergic neurons [86, 88].
However, none of these reports assessed acetyl-CoA content in ALC treated brains. In turn, our data demonstrate that addition of ALC to cultured cholinergic neuroblastoma cells increased acetyl-CoA level in their cytoplasm and prevented A- $\beta$ induced suppression of ACh metabolism (Fig. 2c, d) [55].

Direct interactions between acetyl-CoA and $\mathrm{ACh}$ metabolism were demonstrated by studies on nondifferentiad and cAMP/retinoic acid or NGF-differentiated cholinergic SN56 neuroblastoma cells (Fig. 2c, d). They revealed that differentiation-evoked elevations in their ChAT and ACh were accompanied by suppression of acetyl-CoA level in their mitochondria and its increase in the cytoplasmic compartment (Fig. 2f) [54, 55].

\section{Early and Late Mechanisms of Energy and Acetyl-CoA- Dependent Disturbances in Cholinergic Encephalopathies}

Principal clinical symptoms of $\mathrm{AD}$ and other cholinergic encephalopathies include progressive cognitive deficits leading to dementias, frequently combining with motor disability [89-91]. They correlate well with the degree of functional and structural loses of basal forebrain cholinergic neurons projecting axons to hippocampus and different cortical areas [92]. Another key feature of these pathologies is the suppression of energy metabolism, which correlates with losses of cholinergic markers in affected areas of brain cortex or spinal cord segments. Dysfunction of brain mitochondria is thought to be both the consequence of pathologic insults as well as a source of signals triggering neurodegeneration [93-95]. There is a hypothesis, that particular susceptibility of cholinergic neurons to degeneration results from the fact that their acetyl-CoA, synthesized in mitochondria by PDHC is used not only for energy production in TCA cycle and respiratory chain but also for ACh synthesis in the cytoplasmic compartment (Fig. 2a, b, f) [6, 27, 78, 96].

\section{Alzheimer's Disease}

Alzheimer's disease (AD) is the most frequent form of dementia in senescent population. Estimated number of patients suffering of this pathology reaches 25 million worldwide [97]. AD is a clinical-phenotypic presentation of various sporadic and inherited diseases. Immunohistochemical examinations of autopsied brains reveal accumulation of extracellular amyloid- $\beta$ (A $\beta)$ deposits and neurofibrillary tau protein type degeneration inside the neurons. The amyloidogenic form is $\mathrm{A} \beta_{1-42}$ containing 42 aminoacids, originates from proteolytic processing of transmembrane amyloid precursor protein (APP), by the 
amyloid- $\beta$ cleaving enzyme (BACE1, $\beta$-secretase). Dominating product of APP proteolysis by ADAM ( $\alpha$-secretases) is 26 aminoacid non-amyloidogenic peptide P3 (A $\beta_{17-42}$ fragment) $[98,99]$.

The large fraction of sporadic AD patients is carrying double copies of APOE4 alleles [100, 101]. Moreover, these patients display significant associations with downregulation of multiple transcripts of genes involved in oxidative phosphorylation, energy metabolism as well as with synaptic vesicles docking and fusion [101-103]. AD patients, being APOE4 carriers displayed strong correlation between suppression of KDHC, PDHC and ChAT activities in brain cortex and cognitive dysfunction rate [13, 104]. Reduced activities of PDHC and KDHC in autopsied AD brains displayed strong inverse correlations with clinical dementia rating [13, 105]. Also, glucose Glut 1 and 3 transporters density was reduced in affected brain areas, as demonstrated by in vivo PET and in post mortem cytochalasin B binding studies [106, 107].

The key biochemical and histopathologic finding in $\mathrm{AD}$ brains is preferential loss of cholinergic neurons located in septal nuclei, and their axonal projections to hippocampus and several areas of brain cortex. The decreases of several cholinergic markers such as ChAT, CHT1, VAChT activities and protein levels were observed post mortem in affected brain areas [71, 92, 105, 108]. The loss of cholinergic markers correlated with both suppression of energy metabolism and severity of dementia shown shortly before patient's death $[13,92,108]$. Neuronal loss has been consistently shown in key cholinergic brain nuclei in sixtyseven studies over 20 year period [108]. On the other hand, several noncholinergic transmitter systems were not or much less suppressed by these conditions [109, 110, 111].

Several putative pathomechanisms are involved in $\mathrm{AD}$ encephalopathy. They include: $A \beta_{1-42}$ accumulation, excitotoxicity/NO excess, mitochondrial dysfunction, hypoxia/anoxia/hypoglycaemia, oxygen radicals formation, inflammation, metals $\left(\mathrm{Ca}^{2+}, \mathrm{Zn}^{2+}, \mathrm{Fe}^{2+}, \mathrm{Al}^{3+}\right)$ accumulation, or neurothrophin depletion, which were investigated as cytotoxic signals in AD (Fig. 2) [27, 90, 91, 93, 94, 112118]. Also activation of microglia yielding increased release of proinflamatory interleukins may induce neurodegeneration through Wnt or p75 neurotrophin receptordependent signal transduction pathways $[75,119,120]$. On the other hand, anti-p75/Wnt antibodies or silencing respective genes, protected against excitoxicity/inflammation-induced loss of cholinergic neurons [54, 121].

Most of these cytotoxic signals directly affected activities of enzymes linked with energy and acetyl-CoA metabolism in humans as well as animal and cellular models of AD [13, 27, 96, 102, 104, 118].

Therefore, the key effects of diverse neurodegenerative signals were limitations in acetyl-CoA availability and its intraneuronal distribution, yielding preferential disintegration of cholinergic neurons in AD brains (Figs. 1,2). In fact, suppression of PDHC and mitochondrial energy deficits preceded appearance of $\mathrm{AD}$ pathology in the brains of transgenic 3xTg-AD mice. However, microarray studies revealed that in late-dementive phase of $\mathrm{AD}$ the depression of oxidative phosphorylation was accompanied by up-regulation of those genes [96]. It suggests that down-regulation of energy metabolism in the course of $\mathrm{AD}$ might be a protective response of surviving neurons to decreased supply of glucose and oxygen taking place in this pathology [96].

\section{Excitoxicity}

Several common pathologies of ageing brain like general or focal hypoxia, hypoglyceamia, inflammation, or thiamine deficits, cause depolarization and Ca-overload of neuronal and non neuronal cells. Glutamatergic neurons constitute $50 \%$ of all brain neurons and synaptic terminals [122]. Prolonged pathologic depolarization yields an excessive co-release of glutamate and $\mathrm{Zn}$ from brain "gluzinergic" terminals, triggering action potentials through NMDA, AMPA receptors and other voltage gated $\mathrm{Ca}$ channels located on postsynaptic neurons including cholinergic ones [123-125]. They cause dysfunction of postsynaptic neurons that, when aggravated, may evolve toward apoptosis or necrosis $[126,127]$.

Energy deficits also inhibit uptake of glutamate by adjacent astrocytes, due to the down-regulation of EAA, GLAST and GLT1 transporters and inhibition of their glutamine synthetase [128]. It increases glutamate and $\mathrm{Zn}$ levels within the synaptic clefts, yielding sustained depolarization of postsynaptic neurons, as well as adjacent astroglial and microglial cells [117]. The disruption of $\mathrm{Ca}^{2+}$ homeostasis affects enzymes linked with pathways involved in energy, neurotransmitter, and NO metabolism, which seem to be primary targets for excitotoxic signaling in the brain $[37,38,118]$. The $\mathrm{Ca}^{2+}$ excess in the mitochondrial compartment yields inhibition of PDHC due to activation of PDH kinase, being at least in part, the cause of acetyl-CoA deficits in subcellular compartments of cholinergic neuronal cells (Fig. 2) [27, 38, 129].

\section{Zn Neurotoxicity}

$\mathrm{Zn}$ co-released with glutamate from overexcited "gluzinergic" terminals may reach high, up to 0.3 and $1.0 \mathrm{mmol} /$ $\mathrm{L}$, concentrations in the synaptic cleft $[113,122]$. Subsequently $\mathrm{Zn}$ is avidly taken up from the synaptic cleft by depolarized postsynaptic glial and neuronal cells including cholinergic ones, through the voltage gated, dilthiazemsensitive Ca-channels and specific $\mathrm{Zn}$-transporting proteins [38, 116, 130]. Extended depolarization brings about 
overloading of postsynaptic neurons with $\mathrm{Zn}$, irrespective of expression of their cholinergic phenotype. Zn accumulated in postsynaptic cholinergic neurons was found to inhibit several enzymes of energy metabolism with pathophysiologically relevant potencies including: KDHC > NADP isocitrate dehydrogenase $>$ aconitase $>$ PDHC $[37,38]$. The inhibitory interactions of $\mathrm{Zn}$ with lipoate binding sites of PDHC and KDHC could be reversed by the delayed application of lipoamide or chelating agents. On the contrary, inhibition of aconitase and isocitrate dehydrogenase appeared to be irreversible [37]. Such inhibitory pattern may impede therapeutic attempts aimed to rescue energy metabolism in excitotoxicityaffected brains. Moreover, in human AD brain cortex the alternation pattern of enzymes of energy metabolism appeared to be very similar to that found in Zn-treated SN56 cholinergic cells $[13,37]$. It provides a circumstantial evidence on significance of aberrations in intraneronal distribution of $\mathrm{Zn}$ for the pathomechanism of $\mathrm{AD}$.

The Zn-evoked inhibition of PDHC and other enzymes listed above, explains suppression of mitochondrial acetylCoA levels, and inhibition its metabolic flux through TCA cycle as a cause of ATP depletion and neuronal loss resulting from excitotoxic insults (Table 1; Fig. 2) [37, 38, 125, 126].

Subsequently, deficit of intramitochondrial acetyl-CoA would inhibit transfer of acetyl units to cytoplasm through different pathways (Fig. 1). Shortage of acetyl-CoA, in cytoplasm of cholinergic neurons, may decrease ACh level in this compartment, through ChAT equilibrium mechanism (Table 1; Fig. 2b, c, d) [66]. That in turn would reduce vesicular ACh pool available for quantal release. In this manner overload of postsynaptic cholinergic neurons with $\mathrm{Zn}$ could cause immediate depression of ACh synthesis, as well as its vesicular accumulation and release at early steps of neurodegeneration [46]. On the other hand, chronic excess of $\mathrm{Zn}$ could result in either death of some cholinergic neurons or depression ChAT activity in those surviving in these pathogenic conditions [37, 38]. Our studies revealed that differentiated cholinergic neuronal cells SN56, with high expression of the cholinergic phenotype, were more susceptible to $\mathrm{Zn}$ as well as other neurotoxic signals than those with low level of cholinergic metabolism (Table 1) [27, 38, 131]. This differential, phenotype-dependent susceptibility of septal cholinergic neurons to $\mathrm{Zn}$-induced inputs could be directly linked with insufficient availability of acetyl-CoA in the mitochondrial compartment (Fig. 2a, b) [37, 38].

$\mathrm{Zn}$ itself may also increase $\mathrm{Ca}$ accumulation in the neurons, thereby facilitating opening PTP and release of cytochome c, caspases and other proapoptotic proteins from mitochondria [27, 116, 132]. This excess of $\mathrm{Ca}$ accumulated exclusively in the cytoplasmic compartment of cholinergic neuronal cells in $\mathrm{Zn}$ concentration-dependent pattern [38]. It could trigger PTP formation and aberrant compartmentalization of acetyl-CoA yielding cholinergic neurons injuries [37, 118, 124, 130].

\section{NO Excess}

Gutamate-Zn evoked increase of $\left[\mathrm{Ca}^{2+}\right] /[$ calmodulin-Ca $]$ in cytoplasmic compartments of postsynaptic neurons and adjacent glial cells markedly increases nNOS and eNOS activities, respectively $[113,117]$. It seems however, that only increased expression of Ca-independent iNOS in the microglial/astroglial cells may contribute significantly to neurodegeneration. It has been demonstrated, that only iNOS-dependent activation may elevate the NO levels in the brain up to low micromolar, pathologically relevant, concentrations [113]. In fact, bacterial lipopolysaccharides could induce several-fold increase of NO synthesis by microglia [133]. On the other hand, fraction of NO produced by nNOS/eNOS may reach levels two orders of magnitude lower, and is likely to play a physiologic roles of "volume transmitter" and guanyl cyclase activator [117].

Peroxynitrite radicals were found to react with wide range of intracellular biomolecules linked with energy metabolism, glycolytic metabolism and several regulatory and transport or neurotransmitter functions, as well as with antioxidant systems. Excess of endogenous NO exerts rapid but reversible inhibition of cytochrome $\mathrm{c}$ oxidase and less potent one for other proteins of respiratory chain and ATP-synthetase, as well [113, 117]. However, NO may also inhibit earlier steps of energy metabolism including: PDHC, aconitase, isocitrate NADP-dehydrogenase, as well as KDHC [35, 77, 79]. Other enzymes of TCA cycle: succinate dehydrogenase, fumarase, and malate dehydrogenase were not affected by these conditions. That could cause deficits of acetyl-CoA and ATP in neuronal cells exposed to $\mathrm{NO} / \mathrm{ONOO}^{-}$excess $[77,79]$ Cholinergic neurons with residual expression of the cholinergic phenotype appeared to be more resistant to NO neurotoxicity than those with high expression of the cholinergic phenotype, apparently due to negligible demand for acetyl-CoA to support ACh synthesis in the former (Table 1; Fig. 2f) [35, 77, 79].

Lipoic acid or ALC were found to exert positive effects on viability of NO or Zn treated cholinergic SN56 cells through preservation of high acetyl-CoA levels in their subcellular compartments (Fig. 2) [27, 35]. However, delay in cytoprotectant application markedly diminished their efficacy, apparently due to instant, irreversible inactivation of aconitase by $\mathrm{Zn}$ and NO excess [27, 37, 38]. ChAT appeared to be resistant to direct, acute exposition to NOexcess. However, short exposition of differentiated SN56 
cells to NO excess caused after $24 \mathrm{~h}$ delayed adaptative suppression of ChAT activity, apparently induced by shortages of acetyl-CoA in their mitochondrial and cytoplasmic compartments (Fig. 2b, c, d; Table 1) [15, 27, 77]. Additive effects of NO excess and $\mathrm{A} \beta$ were also observed (Table 1) [79]. Finally, alterations in activities of enzymes of energy metabolism in SNP-treated differentiated SN56 cells displayed pattern, similar to that reported for human AD brains [13, 35, 79]. Also cholinergic cells derived from basal forebrain were more sensitive to NO excess that those originated from brain stem, as indicated by their phospho ERK-2 and DNA fragmentation levels (Table 1) [134]. NO excess increased TUNEL reactivity, lactate dehydrogenase release and the decrease in ChAT activity in primary cholinergic neurons from medial septum, whereas those from brain stem were resistant to such conditions (Table 1) [135-137]. These data indicate that NO-derived radicals may exert differential cholinergic phenotype-specific neurotoxic effects in the brain.

\section{Amyloid- $\beta$ Neurotoxicity}

Accumulation of fibrillar $\mathrm{A} \beta$ deposits in the interstitial compartments of the brain is a hallmark of AD and related amyloid encephalopathies [98, 99, 138]. The disruption of the cholinergic system and suppression of oxidative glucose metabolism were observed in brain regions with $\mathrm{A} \beta$ burden. Therefore, $A \beta$ load was claimed to be the key factor triggering and supporting progress of the disease [98, 99]. However, degree of cognitive impairment correlated much better with loss of cholinergic neurons and impairment of oxidative metabolism than with $\mathrm{A} \beta$ burden in $\mathrm{AD}$ brains [13, 139]. In addition, some cholinergic encephalopathies develop without accumulation of $A \beta$ but with impairment in brain energy metabolism [140-142]. Moreover, AD-type pathologic changes were found to affect about $80 \%$ of individuals of age 65 , but only small fraction of them suffers of dementia [143]. Therefore, $A \beta$ overload in the brain should be treated as diagnostic and staging biomarker, and not as causative factor for this pathology [144, 145]. On the other hand, one cannot exclude possibility that $\mathrm{A} \beta$, after reaching some hypothetical critical level, might aggravate preceding neurotoxic signals, triggering vicious cycle of neurodegeneration. For instance, extracellular fibrillar aggregates of $A \beta$ were found to form autonomic or NMDA-linked high conductance Ca-channels in plasma membranes triggering Ca-dependent mechanisms of cytotoxicity, including depression of energy metabolism [115].

However, effective, cytotoxic concentrations of $A \beta$ in most in vitro experimental conditions appeared to be an order of magnitude higher than those detected in AD brains varying from 0.5 to $4.0 \mu \mathrm{mol} / \mathrm{kg}$ [145-147].
$\mathrm{A} \beta_{1-42}$ in nontoxic, submicromolar concentrations inhibited PDHC and ACh synthesis/release in cultured primary septal neurons, without changing their ChAT activity [148]. This peptide also inhibited oxidative metabolism and decreased ATP contents in the PC12 cells [149]. Short time exposition to high $50 \mu \mathrm{mol} / \mathrm{L} \mathrm{A} \beta$ inhibited glucose uptake and increased synthesis of free radicals in brain synaptosomes [150]. Differential, phenotypedependent susceptibility of neurons to $\mathrm{A} \beta$ was reported by Olesen et al. [151]. They found, that immortalized raphe nucleus neurons, when differentiated to cholinergic phenotype with brain-derived neurotrophic factor became three times more sensitive to $\mathrm{A} \beta$ than those differentiated to serotoninergic phenotype with ciliary neurotrophic factor (Table 1) [151]. In addition, $A \beta$ caused two times greater increase of free $\mathrm{Ca}$ in hippocampal than in cortical neurons [152]. Also injection of $A \beta$ into rat nucleus basalis induced deficits of cholinergic neurons but increased activity of serotoninergic ones [153]. In cerebral neurons, $\mathrm{A} \beta$ inhibited cytochrome P450 epoxygenase, which metabolized arachidonic acid to neuroprotective epoxyeicosatrienoic acid, being inactive toward its cerebellar isoform. Therefore, cerebral and cerebellar neurons appeared to be prone and resistant to $\mathrm{A} \beta$, respectively [154]. Differentiation of cultured embryonal rat brain neurons increased their susceptibility to $A \beta$ [155]. It was due to activation of their cyclin-dependent kinase 5, which promotes tau phosphorylation, responsible for tubulin disintegration in $A \beta$-exposed neurons [155]. There is also known that energy deficits in different pathologies of aging brain induce $\beta$-processing of APP $[94,156]$. On the contrary, dietary high energy substrates were found to reverse neuronal hyperactivity in transgenic AD mice [157]. Studies on differentiated cholinergic SN56 cells revealed that their greater susceptibility to $A \beta$ could be caused by lower activity of PDHC, yielding decreased availability of acetyl-CoA in their mitochondria. In addition, high basal levels of $\mathrm{Ca}$ both in mitochondrial and cytoplasmic compartments of differentiated cells, could facilitate detrimental effects of $A \beta$ (Fig. 2a, e; Table 1) [27, 55, 79]. Also increased expression of $\mathrm{p} 75$ receptors in differentiated cells could augment their sensitivity to $A \beta$ in the presence of NGF $[27,54,158]$. There are also indications that $A \beta$ may aggravate neurotoxic effects of other AD-linked toxins such as $\mathrm{Al}, \mathrm{Zn}$ or peroxinitrine radicals (see "Zn Neurotoxicity", "NO Excess") [79, 113, 118, 159]. It has been found, that $\mathrm{A} \beta, \mathrm{Al}$ or $\mathrm{NO}$ excess exerted cumulative suppressive effects on PDHC and aconitase activities, acetylCoA levels, cholinergic metabolism and viability cholinergic SN56 cells in culture (Figs. 1, 2) [27, 79, 118].

On the other hand, regional accumulation of $A \beta$ in human $\mathrm{AD}$ brain did not correlate with loss of respective cognitive functions [139, 160]. Accordingly, in number of patients 
with heavy $\mathrm{A} \beta$ load, but with normal deposition of amyloid $\mathrm{P}$ in the brain cortex and hippocampus, no signs of dementia have been found. On the other hand, individuals with moderate $A \beta$ accumulation and high content of amyloid $P$ displayed typical symptoms of AD dementia [161].

Also in $3 \times \mathrm{TgAD}$ mice cognitive impairment appeared before formation any $A \beta$ and tau deposits in their brains [162]. Apparently, A $\beta$ accumulation should be considered rather as an outcome than a trigger of $\mathrm{AD}$ neurodegeneration [145, 163]. However, it does not exclude possibility that accumulated $A \beta$ might in combination with earlier cytotoxic signals aggravate end stages of cholinergic encephalopathies.

\section{Transgenic Animal Models of Cholinergic Degeneration}

Several transgenic mice ( $\mathrm{Tg}$ ) models have been developed to study mechanisms of $A \beta$-dependent neurodegeneration and investigate putative therapeutic approaches to AD. All of Tgs were designed by single or multiple inserts of mutated APP, PS1 human gen(s) into mice germinal cells. If the above assumptions are correct, then Tg-AD mice should display: (1) A $\beta$ accumulation in sensitive areas of the brain cortex in their advanced age, (2) functional and structural disruption of cholinergic neurons paralleling deficits of cognitive functions, (3) suppression of energy metabolism preceding alterations, quoted above.

1. There are significant discrepancies concerning accumulation of $A \beta_{1-42}$ in brains of $\mathrm{Tg}$ animals. For instance, in brains of $\operatorname{Tg} 2576$ mice, $A \beta_{1-42}$ levels reported by different authors varied from 0.13 through $0.94 \mu \mathrm{mol} / \mathrm{kg}$ to over 200 times higher concentrations of $30 \mu \mathrm{mol} / \mathrm{kg}$ of tissue (Table 1) [164-166]. What is interesting, the degree of cognitive impairment, and histochemical amyloid plaque densities were similar in all strains. Also, strikingly wide range of $A \beta_{1-42}$ levels was reported for post mortem AD human brains [146, 167]. Such wide dispersion of patholologic values may, presumably result from still existing analytical problems concerning $A \beta$ recovery, matrix effects, standardization, or specificity and avidity of used antibodies.

2. There are also significant differences between alterations in cholinergic marker levels in human AD and mice $\mathrm{Tg}$ brains. In human AD brains, significant decreases in ChAT activities and other cholinergic markers correlated with loss of cognitive functions (see "Alzheimer's disease"). On the other hand, no losses of ChAT activity and VAChT levels were observed in brains of demented Tg-AD or TS65DN mice despite evident cognitive deficits [168, 169]. However, decreases in $\mathrm{ACh}$ content and release rates were found in Tg-AD mentally impaired mice, despite of normal ChAT activity [166, 170].

3. The inhibition of glucose uptake and pyruvate utilization in FVB mice took place, which was likely to cause deficits of acetyl-CoA for energy and ACh production (Table 1) [171]. However, no suppressions in PDHC, aconitase, ICDH-NADP and KDHC activities were found in brains of 17 months $\mathrm{Tg} 2576$ mice (Table 1) [165] (Szutowicz, Schliebs unpublished). They remain in contrast with findings in human AD brains, which revealed significant decreases in activities of all enzymes listed above [13]. Data presented here indicate that in $\mathrm{Tg}$ mice structural integrity of cholinergic neurons is better preserved than in human $\mathrm{AD}$ brains. Thus, suppression of $\mathrm{ACh}$ metabolism and dependent cognitive functions in $\mathrm{Tg}$-mice is of functional character, resulting from relatively weak inhibition of glucose and pyruvate metabolism by accumulating $A \beta$, which is not deadly to cholinergic neurons [14, 171, 172].

\section{Thiamine Deficiency Encephalopathy}

Animals and humans have no capacity of thiamine ring synthesis, which is the precursor of thiamine diphosphate (TDP). TDP is a cofactor of two key enzymes of energy metabolism PDHC and KDHC, providing acetyl-CoA for and limiting metabolic flux through TCA cycle, respectively. Therefore, thiamine deficits (TD) impair functions of all body tissues, yielding multi symptomatic and diverse clinical presentations of cholinergic transmission deficits. There are claims that, TD-induced inhibition of oxidative metabolism might facilitate and exacerbate amyolid plaque pathology [156, 173, 174]. In consequence, alcohol abuse, which is a most common worldwide cause of TD, should be considered as a risk factor for $\mathrm{AD}$ [175].

\section{Energy and Acetyl-CoA Metabolism in Thiamine Deficient Brain}

Early studies on pyrithiamine-TD rat brains reported either no change or slight decrease of acetyl-CoA levels [48, 176]. They however, addressed neither intercellular nor intracellular compartmentalization of this metabolite. So far, only few studies provided quantitative data on mitochondrial and cytoplasmic pools of acetyl-CoA in different cellular compartments in TD (Table 1, Figs. 1, 2) [36, 131].

In TD brains two major mechanisms seem to contribute to an early dysfunction and late loss of cholinergic neurons. They include: primary limitation of acetyl-CoA provision by unproductive TD-PDHC and secondary excitotoxic over-activation by glutamate- $\mathrm{Zn}$ released from energy-depleted 
glutamatergic neurons [37, 122]. The combination of TDevoked, direct inhibition of PDHC and KDHC and Zn-induced excitotoxicity may aggravate acetyl-CoA and energy shortages in these conditions [36, 38, 128, 177]. In such conditions reductions in intramitochondrial levels of acetyl-CoA correlated with loses of cholinergic markers and viability of cholinergic neuronal cells (Fig. 2a, b, d) [15, 27, 36-38, 131].

There is well established, that the decrease of cytoplasmic acetyl-CoA in TD SN56 cells and brain nerve terminals resulted from limited availability of this metabolite in the mitochondrial compartment (Figs. 1, 2b, c). In consequence, lower rates of ACh release in TD neurons positively correlated with decreased concentration of acetyl-CoA in their cytoplasmic compartment (Fig. 2d) $[38,131]$. These findings fit to a general rule that the rate of ACh synthesis/release depends on the availability of acetyl-CoA in cytoplasmic/synaptoplasmic compartment of cholinergic neurons, irrespective of neurotoxic signal (Figs. 1, 2c, d) [6, 27, 118]. However, unlike for AD or other neurotoxic conditions, acute TD altered ChAT activity neither in pyrithiamine-rat brain synaptosomes nor in amprolium-SN56 cells [38, 131, 176, 178]. These data indicate that, at least in early stages of $\mathrm{TD}$, the structure of cholinergic neurons remained well preserved.

Also in this model of cholinergic pathology, neurons with high expression of the cholinergic phenotype appeared to be more susceptible to TD than those with residual cholinergic activity. There was in line with lower levels of mitochondrial acetyl-CoA in the DC (Fig. 2c; Table 1) [131]. Residual ACh metabolism in nondifferentiated cholinergic neurons was not affected by TD-induced shortages in mitochondrial and cytoplasmic acetyl-CoA (Table 1, Figs. 1, 2c, d, e) [130]. Other, in vivo observations on differential regional susceptibility of brain cholinergic neurons and energy metabolism to TD remain in accord with cell culture studies [1, 156, 179].

\section{Choline}

Choline is another precursor of $\mathrm{ACh}$, which is utilized in equivalent amounts with acetyl-CoA for the transmitter synthesis. Mammalian brain has limited capacity to synthesize its own choline. Therefore, this ACh precursor has to be transported from intravascular compartment across the blood brain barrier [180, 181]. Cholinergic neuron axonal terminals possess highest density CHT1 that are specific functional proteins for their axonal terminals [182, 183]. It has been suggested, that only choline transported by CHT1 is available for ACh synthesis.

In pathological conditions, prolonged depolarization of cholinergic terminals may inhibit CHT1-dependent transport of choline from extracellular space due to collapse of membrane potential. In such conditions, choline may originate from hydrolysis of structural membrane phospholipids by phospholipase D [181]. This choline pool could supplement ACh synthesis and maintain stable transmitter level during its excessive release in course of sustained depolarization of cholinergic neurons. However, if such conditions persist the phosphatidylcholine content in membranes of cholinergic neurons would decrease, resulting in their shrinkage and death [181]. That could contribute to particular susceptibility of cholinergic neurons to neurodegenerative insults [181]. On the contrary, the increase of extracellular choline to supraphysiological concentrations increased both basal and depolarizationevoked ACh release. It indicates, that choline taken up by low affinity system could also be used for transmitter synthesis and release. These observations rationalize use of choline supplementation as a method improving $\mathrm{ACh}$ metabolism in age-evoked disturbances of cholinergic system in the brain $[184,185]$. Unlike acetyl-CoA, choline provision for ACh synthesis is not directly dependent on the energy production. However, correction of acetyl-CoA and energy deficits in aged rats by ALC supply in drinking water elevated choline uptake as well as ACh synthesis and release [85, 182].

On the other hand, choline-deficient diets induced deficits of this precursor both in cell membranes and in the ACh synthesizing compartment [186]. Lack of membrane integrity could cause the impairment of energy production in brain mitochondria, leading to increased vulnerability of cholinergic neurons to neurodegenerative signals along with appearance of behavioral deficits [186, 187]. Such reciprocal interactions between aberrant acetyl-CoA/ energy and choline metabolisms may trigger vicious cycle of early deterioration of cholinergic neurons under various neurodegenerative conditions.

\section{Future Directions}

Vast number of studies has been performed over the past three decades on the mechanisms of $\mathrm{AD}$ and other cholinergic encephalopaties. They employed diverse in vivo, in vitro models, and clinical studies focused mainly on disturbances in $A \beta$ metabolism. Only small fraction of them focused on malfunctions of energy metabolism and their role in onset and progress of $\mathrm{AD}$. The latter reveal decreases in PDHC and KDHC activities, which depress acetyl-CoA synthesis and utilization, in regions of brain cortex affected by this pathology [27, 118]. There is however a significant time gap between observations on acute, excitotoxic alterations in energy metabolism and late structural, irreversible changes in the neuronal network [188]. Therefore, several questions remain to be answered 
regarding time-course transition mechanisms between early, apparently reversible stages of inhibition of acetylCoA/energy production and delayed, irreversible phase of impairment of brain cholinergic system. To address this problem multiple time and neurotoxin dose-dependent studies on expression and postranlational modifications in enzymes/proteins of energy metabolism and intracellular signal transduction pathways should be executed. Further studies are also necessary on reciprocal, differential acute and chronic effects of AD pathology on energy/acetyl-CoA metabolism in dominating class of glutamatergic neurons as well as astro and microglial cells to link them with acute and prolonged abberations in their functions and integrity. They should provide a detailed map of regional and inter/ intracellular compatrmentalization of acetyl-CoA in the brain. This might pave the path for studies on interventions aiming to preserve acetyl group metabolism, in manner adequate to early and late stages of neurodegeneration.

Acknowledgments Work was supported by MNiSW projects 2011 046071 and NN401 029937 and GUMed fund St-57.

Open Access This article is distributed under the terms of the Creative Commons Attribution License which permits any use, distribution, and reproduction in any medium, provided the original author(s) and the source are credited.

\section{References}

1. Butterworth RF, Giguere JF, Besnard AM (1985) Activities of thiamine-dependent enzymes in two experimental models of thiamine-deficiency encephalopathy: 1 . The pyruvate dehydrogenase complex. Neurochem Res 10:1417-1428

2. Szutowicz A, Stępień M, Bielarczyk H, Kabata J, Łysiak W (1982) ATP citrate lyase in cholinergic nerve endings. Neurochem Res 7:799-810

3. Szutowicz A, Łysiak W (1980) Regional and subcellular distribution of ATP-citrate lyase and other enzymes of acetyl-CoA metabolism in rat brain. J Neurochem 35:775-785

4. Duelli R, Kuschinsky W (2001) Brain glucose transporters: relationship to local energy demand. News Physiol Sci 16:71-76

5. Roberts EL Jr (2007) The support of energy metabolism in the central nervous system with substrates other than glucose. In: Lajtha A, Gibson GE, Dienel GA (eds) Handbook of neurochemistry and molecular neurobiology. Brain energetics. Integration of molecular and cellular processes. Springer, Berlin, pp 139-179

6. Szutowicz A, Tomaszewicz M, Bielarczyk H (1996) Disturbances of acetyl-CoA, energy and acetylcholine metabolism in some encephalopathies. Acta Neurobiol Exp 56:323-339

7. Szutowicz A, Tomaszewicz M, Jankowska A, Kisielevski Y (1994) Acetylcholine synthesis in nerve terminals of diabetic rats. NeuroReport 5:2421-2424

8. Serres S, Raffard G, Franconi JM, Merle M (2008) Close coupling between astrocytic and neuronal metabolomics to fulfill anaplerotic and energy needs in the rat brain. J Cereb Blood Flow Metab 28:712-724

9. Halestrap AP, Wilson MC (2012) The monocarboxylate transporter family - role and regulation. IUBMB Life 64:109-119
10. Wohnsland S, Burgers HF, Kuschinsky W, Maurer MH (2010) Neurons and neuronal stem cells survive in glucose-free lactate and in high glucose cell culture medium during normoxia and anoxia. Neurochem Res 35:1635-1642

11. Dienel GA (2011) Brain lactate metabolism: the discoveries and the controversies. J Cereb Blood Flow Metab 32:1107-1138

12. Baslow MH (2007) N-acetylaspartate and N-acetylaspartylglutamate. In: Oja SS, Schousboe A, Saransaari P (eds) Handbook of neurochemistry and molecular biology. Amino acids and peptides in the nervous system, 3rd edn. Springer, New York, pp 305-346

13. Bubber P, Haroutunian V, Fisch G, Blass JP, Gibson GE (2005) Mitochondrial abnormalities in Alzheimer brain: mechanistic implications. Ann Neurol 57:695-703

14. Szutowicz A, Tomaszewicz M, Bielarczyk H, Jankowska A (1998) Putative significance of shifts in acetyl-CoA compartmentalization in nerve terminals for disturbances of cholinergic transmission in brain. Devel Neurosci 20:485-492

15. Szutowicz A, Tomaszewicz M, Jankowska A, Madziar B, Bielarczyk H (2000) Acetyl-CoA metabolism in cholinergic neurons and their susceptibility to neurotoxic inputs. Met Brain Dis $15: 29-44$

16. Bhatt DP, Houdek HM, Watt JA, Rosenberger TA (2013) Acetate supplementation increases brain phosphocreatine and reduces AMP levels with no effects on mitochondrial biogenesis. Neurochem Int 62:296-305

17. Soliman ML, Ping KL, Combs CK, Rosenberger TA (2012) Acetate reduces microglia inflammatory signaling in vitro. J Neurochem 123:555-567

18. Deelchand DK, Nelson C, Shestov AA, Ugurbil K, Henry PG (2009) Simultaneous measurement of neuronal and glial metabolism in rat brain in vivo using co-infusion of [1,6-13C]glucose and [1,2,-13C]acetate. J Magn Reson 196:157-163

19. Laughton JD, Bittar P, Charnay Y, Pellerin L, Kovari E, Magistretti PJ, Bouras C (2007) Metabolic compartmentalization in the human cortex and hippocampus: evidence for a cell- and region-specific localization of lactate dehydrogenase 5 and pyruvate dehydrogenase. BMC Neurosci 8:35

20. Halim ND, McFate T, Mohyeldin A, Okagaki P, Korotchkina LG, Patel MS, Jeoung NH, Harris RA, Schell MJ, Verma A (2010) Phosphorylation status of pyruvate dehydrogenase distinguishes metabolic phenotypes of cultured rat brain astrocytes and neurons. Glia 58:1168-1176

21. Gandhi GK, Cruz NF, Ball KK, Dienel GA (2009) Astrocytes are poised for lactate trafficking and release from activated brain and for supply of glucose to neurons. J Neurochem 111:522-536

22. Pellerin L (2003) Lactate as a pivotal element in neuron-glia metabolite cooperation. Neurochem Int 43:331-338

23. Bergersen LH (2007) Is lactate food for neurons? Comparison of monocarboxylate transporter subtypes in brain and muscle. Neuroscience 145:11-19

24. Sonnewald U, Schousboe A, Qu H, Waagepetersen HS (2004) Intracellular metabolic compartmentation assessed by ${ }^{13} \mathrm{C}$ magnetic resonance spectroscopy. Neurochem Int 45:305-310

25. Leong SF, Lai JCK, Lim L, Clark JB (1981) Energy-metabolising enzymes in brain regions of adult and aging rats. J Neurochem 37:1548-1556

26. Szutowicz A, Jankowska A, Blusztajn JK, Tomaszewicz M (1999) Acetylcholine and acetyl-CoA metabolism in differentiating SN56 septal cell line. J Neurosci Res 57:131-136

27. Szutowicz A, Bielarczyk H, Gul S, Ronowska A, Pawełczyk T, Jankowska-Kulawy A (2006) Phenotype-dependent susceptibility of cholinergic neuroblastoma cells to neurotoxic inputs. Metab Brain Dis 21:149-161

28. Cremer JE, Teal HM (1974) The activity of pyruvate dehedrogenase in rat brain during postnatal development. FEBS Lett 39:17-20 
29. Malloch GDA, Munday LA, Olson MS, Clark JB (1986) Comparative development of the pyruvate dehydrogenase complex and citrate synthase in rat brain mitochondria. Biochem J 238:729-736

30. Buerstatte CR, Behar KL, Novotny EJ Jr, Lai JCK (2000) Brain regional development of the activity and $\alpha$-ketoglutarate dehydrogenase complex in the rat. Devel Brain Res 125: 139-145

31. Szutowicz A, Kabata J, Łysiak W (1980) ATP citrate lyase and other enzymes of acetyl-CoA metabolism in developing rat cerebrum and cerebellum. Int J Biochem 11:545-549

32. Albers DS, Beal MF (2000) Mitochondrial dysfunction and oxidative stress in aging and neurodegenerative disease. J Neural Transm [Suppl] 59:133-154

33. Di Domenico F, Perluigi M, Butterfield DA, Cornelius C, Calabrese V (2010) Oxidative damage in rat brain during aging: interplay between energy and metabolic key target proteins. Neurochem Res 35:2184-2192

34. Uranga RM, Bruce-Keller AJ, Morrison CD, Fernandez-Kim SO, Ebenezer PJ, Zang L, Dasuri K, Keller JN (2010) Intersection between metabolic dysfunction, high fat diet consumption and brain aging. J Neurochem 114:344-361

35. Bielarczyk H, Gul S, Ronowska A, Bizon-Zygmańska D, Pawełczyk T, Szutowicz A (2006) RS- $\alpha$-lipoic amid protects cholinergic cells against sodium nitroprusside and amyloid- $\beta$ neurotoxicity through restoration of acetyl-CoA level. J Neurochem 98:1242-1251

36. Jankowska-Kulawy A, Bielarczyk H, Pawełczyk T, Wróblewska M, Szutowicz A (2010) Acetyl-CoA and acetylcholine metabolism in nerve terminal compartment of thiamine deficient rat brain. J Neurochem 115:333-342

37. Ronowska A, Gul-Hinc S, Bielarczyk H, Pawełczyk T, Szutowicz A (2007) Effects of zinc on SN56 cholinergic neuroblastoma cells. J Neurochem 103:972-983

38. Ronowska A, Dyś A, Jankowska-Kulawy A, KlimaszewskaŁata J, Bielarczyk H, Romianowski P, Pawełczyk T, Szutowicz A (2010) Short-term effects of zinc on acetylcholine metabolism and viability of SN56 cholinergic neuroblastom cells. Neurochem Int 56:143-151

39. Paradies G, Pertosillo G, Paradies V, Ruggiero FM (2011) Mitochondrial dysfunction in brain aging: role of oxidative stress and cardiolipin. Neurochem Int 58:447-457

40. Zhou Q, Lam PY, Han D, Cadenas E (2009) Activation of c-Jun$\mathrm{N}$-terminal kinase and decline of mitochondrial pyruvate dehydrogenase activity during brain aging. FEBS Lett 583 :1132-1140

41. Guynn RW, Gelberg HJ, Veech R (1973) Equilibrium constants of the malate dehydrogenase, citrate synthase, citrate lyase, and acetyl-CoA hydrolysis reactions under physiological conditions. J Biol Chem 248:6957-6965

42. Choi CH, Zimon A, Usheva A (2005) Metabolic stress regulates basic transcription through acetyl-coenzyme A. Cell Mol Life Sci 62:625-628

43. Ricny J, Tucek S (1980) Relation between the content of acetylcoenzyme $\mathrm{A}$ and acetylcholine in brain slices. Biochem $\mathrm{J}$ 188:683-688

44. Szutowicz A, Łysiak W, Angielski S (1977) Effect of (-)hydroxycitrate on pyruvate metabolism in rat brain synaptosomes. J Neurochem 29:375-378

45. Bielarczyk H, Szutowicz A (1989) Evidence for the regulatory function of synaptoplasmic acetyl-CoA in acetylcholine synthesis in nerve endings. Biochem J 262:377-380

46. Deutsch J, Rapoport SI, Rosenberger TA (2003) Valproyl-CoA and estrified valproic acid are not found in brains of rats treated with valproic acid, but the brain concentrations of $\mathrm{CoA}$ and acetyl-CoA are altered. Neurochem Res 28:861-866
47. Kato T (1978) Ischemic effect on CoASH and acetyl-CoA concentration levels in cerebrum, cerebellum and liver of mice. J Neurochem 31:1545-1547

48. Reynolds SF, Blass JP (1975) Normal levels of acetyl coenzyme A and acetylcholine in the brains of thiamine deficient rats. J Neurochem 24:185-186

49. Ricny J, Tucek S (1981) Acetyl-coenzyme A and acetylcholine in slices of rat caudate nuclei incubated in the presence of metabolic inhibitors. J Biol Chem 256:4919-4923

50. Ricny J, Tucek S (1983) $\mathrm{Ca}^{2+}$ ions and the output of acetyl-CoA from brain mitochondria. Gen Physiol Biophys 2:27-37

51. Shea PA, Aprison MH (1977) The distribution of acetyl-CoA in specific areas of the CNS of the rat and measured by modification od a radio-enzymatic assay for acetylcholine and choline. J Neurochem 28:51-58

52. Schuberth J, Sollenberg J, Sundwall A, Sorbo B (1966) Acetylcoenzyme A in brain. The effect of centrally active drugs, insulin coma and hypoxia. J Neurochem 16:819-822

53. Szutowicz A, Bielarczyk H (1987) Elimination of CoA-SH interference from acetyl-CoA assay by maleic anhydride. Anal Biochem 164:292-296

54. Szutowicz A, Madziar B, Pawełczyk T, Tomaszewicz M, Bielarczyk H (2004) Effect of NGF on acetylcholine, acetyl-CoA metabolism, and viability of differentiated and non-differentiated cholinergic neuroblastom cells. J Neurochem 90:952-961

55. Szutowicz A, Bielarczyk H, Gul S, Zieliński P, Pawełczyk T, Tomaszewicz M (2005) Nerve growth factor and acetyl-L-carnitine evoked shifts in acetyl-CoA and cholinergic SN56 cell vulnerability to neurotoxic inputs. J Neurosci Res 79:185-192

56. Bielarczyk H, Tomaszewicz M, Szutowicz A (1998) Effect of aluminium on acetyl-CoA and acetylcholine metabolism in nerve terminals. J Neurochem 70:1175-1181

57. Srere PA (1965) The molecular physiology of citrate. Nature 205:766-770

58. Tucek S, Dolezal V, Sullivan AC (1981) Inhibition of the synthesis of acetylcholine in rat brain slices by (-)hydroxycitrate and citrate. J Neurochem 36:1331-1337

59. Dolezal V, Tucek S (1981) Utilization of citrate acetylcarnitine, acetate and glucose for the synthesis of acetylcholine in rat brain slices. J Neurochem 36:1323-1330

60. Ricny J, Tucek S, Novakova J (1992) Acetylcarnitine, carnitine and glucose diminish the effect of muscarinic antagonist quinuclidinyl benzilate on striatal acetylcholine content. Brain Res 576:215-219

61. Scafidi S, Fiskum G, Lindauer SL, Bamford P, Shi D, Hopkins I, McKenna MC (2010) Metabolism of acetyl-L-carnitine for energy and neurotransmitter synthesis in the immature brain. J Neurochem 114:820-831

62. Barsukova A, Komarov A, Hajnoczky G, Bernardi P, Bourdette D, Forte M (2011) Activation of the mitochondrial permeability transition pore modulates $\mathrm{Ca}^{2+}$ responses to physiological stimuli in adult neurons. Eur J Neurosci 33:831-842

63. Madhavarao NC, Chinopoulos C, Chandrasekaran K, Namboodiri MAA (2003) Characterization of the $N$-acetylaspartate biosynthetic enzyme from rat brain. J Neurochem 86:824-835

64. Watanabe T, Shiino A, Akiguchi I (2012) Hippocampal metabolites and memory performances in patients with amnestic mild cognitive impairment and Alzheimer's disease. Neurobiol Learn Mem 97:289-293

65. Wellen KE, Hatzivassiliou G, Sachdeva UM, Bui TV, Cross JR, Thompson CB (2009) ATP-citrate lyase links cellular metabolism to histone acetylation. Science 324:1076-1080

66. Tucek S (1993) Short-term control of the synthesis of acetylcholine. Prog Biophys Molec Biol 60:59-69

67. Eiden LE (1998) The cholinergic gene locus. J Neurochem $70: 2227-2240$ 
68. Hartikka J, Hefti F (1988) Development of septal cholinergic neurons in culture: plating density and glial cells modulate effects of NGF on survival, fiber growth, and expression of transmitter specific enzymes. J Neurosci 8:2967-2985

69. Auld DS, Mennicken F, Quirion R (2001) Nerve growth factor rapidly induces prolonged acetylcholine release from cultured basal forebrain neurons: differentiation between neuromodulatory and neurotrophic influences. J Neurosci 21:3375-3382

70. Yamada T, Inazu M, Tajima H, Matsumiya T (2011) Functional expression of choline transporter-like protein 1 (CTL1) in human neuroblastom cells and its link to acetylcholine synthesis. Neurochem Int 58:354-365

71. Efange SMN, Garland EM, Stanley JK, Khare AB, Mash DC (1997) Vesicular acetylcholine transporter density and Alzheimer's disease. Neurobiol Aging 18:407-413

72. Schliebs R, Arendt T (2006) The significance of the cholinergic system in the brain during aging and Alzheimer's disease. J Neural Transm 113:1625-1644

73. Vanucchi MG, Pepeu G (1987) Effect of phosphatidylserine on acetylcholine release and content in cortical slices from aging rats. Neurobiol Aging 8:403-407

74. Wang F, Chen H, Sun X (2009) Age-related spatial cognitive impairment is correlated with a decrease in ChAT in cerebral cortex, hippocampus and forebrain of SAMP8 mice. Neurosci Lett 454:212-217

75. Fortress AM, Buhusi M, Helke KL, Granholm ACE (2011) Cholinergic degeneration and alterations in the TrkA and p75NTR balance as a result of pro-NGF injection into aged rats. J Aging Res. doi:10.4061/2011/460543

76. Richardson PJ (1981) Quantitation of cholinergic synaptosomes from guinea pig brain. J Neurochem 37:258-260

77. Bielarczyk H, Tomaszewicz M, Madziar B, Ćwikowska J, Pawełczyk T, Szutowicz A (2003) Relationships between cholinergic phenotype and acetyl-CoA level in hybrid Marine neuroblastoma cells of sep tal origin. J Neurosci Res 73:717-721

78. Lefresne P, Guyenet P, Glowinski J (1973) Acetylcholine synthesis from $\left[2-{ }^{14} \mathrm{C}\right]$ pyruvate in rat striatal slices. J Neurochem 20:1083-1097

79. Bielarczyk H, Jankowska A, Madziar B, Matecki A, Michno A, Szutowicz A (2003) Differential toxicity of nitric oxide, aluminum and amyloid-beta peptide in SN56 cholinergic cells from mouse septum. Neurochem Int 42:323-331

80. Cai L, Sutter BM, Li B, Tu BP (2010) Acetyl-CoA induces cell growth and proliferation by promoting the acetylation of histones at growth genes. Mol Cell 42:426-437

81. Irwin DJ, Cohen TJ, Grossman M, Arnold SE, Xie SX, Lee VMY, Trojanowski JQ (2012) Acetylated tau, a novel pathological signature in Alzheimer's disease and other tauopathies. Brain 135:807-818

82. Szutowicz A, Srere PA, Allen CN, Crawford IL (1982) Effects of septal lesions on enzymes of acetyl-CoA metabolism in the cholinergic system of the rat hippocampus. J Neurochem 39:458-463

83. Szutowicz A, Morrison MR, Srere PA (1983) The enzymes of acetyl-CoA metabolism in differentiating cholinergic (S-20) and noncholinegric (NIE-1150 neuroblastoma cells. J Neurochem 40:1664-1770

84. Selwyn MJ (1987) Holes in mitochondrial inner membranes. Nature 330:424-425

85. Ando S, Tadenuma T, Tanaka Y, Fukui F, Kobayashi S, Ohashi Y, Kawabata T (2001) Enhancement of learning capacity and cholinergic synaptic function by carnitine in aging rats. J Neurosci Res 66:266-271

86. Aureli T, Miccheli A, Ricciolini R, DiCocco ME, Ramacci MT, Agelucci L, Ghirardi O, Conti F (1990) Aging brain: effect of acetyl-L-carnitine treatment on rat brain energy and phospholipid metabolism. A study by ${ }^{31} \mathrm{P}$ and ${ }^{1} \mathrm{H}$ NMR spectroscopy. Brain Res 526:108-112

87. Smeland OB, Meisingset TW, Sonnewald U (2012) Dietary supplementation with acetyl-L-carnitine in seizure treatment of phenylenetetrazole kindled mice. Neurochem Int 61: 444-454

88. Pettegrew JW, Klunk WE, Panchalingam K, Kanfer JM, McClure RJ (1995) Clinical and neurochemical effects of acetyl-Lcarnitine in Alzheimer's disease. Neurobiol Aging 16:1-4

89. Crochemore C, Pena-Altamira E, Virgili M, Monti B, Contestabile A (2005) Disease-related regressive alterations of forebrain cholinergic system in SOD1 mutant transgenic mice. Neurochem Int 46:357-368

90. Fiskum G, Murphy AN, Beal FM (1999) Mitochondria in neurodgeneration: acute ischemia an chronic neurodegenerative deiseases. J Cereb Bood Flow Metab 19:351-369

91. Martin LJ (2010) Mitochondrial pathobiology in Parkinson's disease and amyotrophic lateral sclerosis. J Alzheimer's Dis 20:S335-S356

92. Pappas BA, Bayley PJ, Bui BK, Hansen LA, Thal LJ (2000) Choline acetyltransferase activity and cognitive domain scores of Alzheimer's patients. Neurobiol Aging 21:11-17

93. Higgins GC, Beart PM, Shin YS, Chen MJ, Cheung NS, Nagley P (2010) Oxidative stress: emerging mitochondrial and cellular themes and variations in neuronal injury. J Alzheimer's Dis 20(Suppl 2):S453-S473

94. Lin MT, Beal MF (2006) Mitochondrial dysfunction and oxidative stress in neurodegenerative diseases. Nature 443:787-795

95. Morais VA, De Strooper B (2010) Mitochondrial dysfunction and neurodegenerative disorders: cause or consequence. J Alzheimer's Dis 20(Suppl 2):S255-S263

96. Sun J, Feng X, Liang D, Duan Y, Lei H (2012) Down-regulation of energy metabolism in Alzheimer's disease is a protective response of neurons to the microenvironment. J Alzheimer's Dis 28:389-402

97. Hoyer S, Frolich I (2007) Dementia: the significance of cerebral metabolic disturbances in Alzheimer's disease. Relation to Parkinson's disease. In: Lajtha A, Moussa BH, Riederer P, Mandel SA, Battistin L (eds) Handbook of neurochemistry and molecular biology 3rd edition, degenerative diseases of the nervous system. Springer, New York, pp 189-232

98. Selkoe DJ (1994) Alzheimer's disease: a central role of amyloid. J Neuropath Exp Neurol 53:438-449

99. Walsh DM, Selkoe DJ (2007) A $\beta$ oligomers-a decade of discovery. J Neurochem 101:1172-1184

100. Xu PT, Li YJ, Qin XJ, Scherzer CR, Xu H, Schmechel DE, Hulette CM, Ervin J, Gullans SR, Haines J, Peicak-Vance MA, Gilbert JR (2006) Differences in apolipoprotein E3/3 and E4/E4 allele-specific gene expression in hippocampus in Alzheimer's disease. Neurobiol Dis 21:256-275

101. Bertram L, McQueen MB, Mullin K, Blacker D, Tanzi RE (2007) Systematic meta-analyses of Alzheimer disease genetic association studies: the AlzGene database. Nature Gen 39:17-23

102. Manji H, Kato T, Di Prospero NA, Ness S, Beal MF, Krams M, Chen G (2012) Impaired mitochondrial function in psychiatric disorders. Nature Rev Neurosci 13:293-307

103. Chen HK, Ji YS, Dodson SE, Miranda RD, Rosenblum CI, Reynolds IJ, Freedman SB, Weisgraber KH, Huang Z, Mahlez RW (2011) Apolipoprotein E4 domain interaction, mediates detrimental effects on mitochondria and is a potential therapeutic target for Alzheimer disease. J Biol Chem 286:5215-5221

104. Gibson GE, Haroutunian V, Zang H, Park LCH, Shi Q, Lesser M, Mohs RC, Sheu RKF, Blass JP (2000) Mitochondrial damage in Alzheimer's disease varies with apolipoprotein E genotype. Ann Neurol 48:297-303 
105. Terwel D, Bothmer J, Wolf E, Meng F, Jolles J (1998) Affected enzyme activities in Alzheimer's disease are sensitive to antemortem hypoxia. J Neurol Sci 161:47-56

106. Benson DF (1983) Alterations in glucose metabolism in Alzheimer's disease. Banbury report 15. Cold Spring Harbor Laboratory, pp 309-315

107. Kalaria RN, Harik SI (1989) Reduced glucose transporter at blood-brain barrier and in cerebral cortex in Alzheimer's disease. J Neurochem 53:1083-1088

108. Bierer LM, Haroutunian V, Gabriel S, Knott PJ, Carlin LS, Purohit DP, Perl DP, Schmeidler J, Kanof P, Davis KL (1995) Neurochemical correlates of dementia severity in Alzheimer's disease: relative importance of cholinergic deficits. J Neurochem 64:749-760

109. Armstrong DM, Sheffield R, Mishizen-Eberz AJ, Carter TL, Rissman RA, Mizukami K, Ikonomovic MD (2003) Plasticity of glutamate and $\mathrm{GABA}_{\mathrm{A}}$ receptors in the hippocampus of patients with Alzheimer's disease. Cell Mol Neurobiol 23:491-505

110. Lyness SA, Zarow C, Chui HC (2003) Neuron loss in key cholinergic and aminergic nuclei in Alzheimer disease: a metaanalysis. Neurobiol Aging 24:1-23

111. Francis PT, Palmer AM, Snape M, Wilcock GK (1999) The cholinergic hypothesis of Alzheimer's disease: a review of progress. J Neurol Neurosurg Psychiatry 66:137-147

112. Kar S, Slowikowski S, Westway D, Mount HTJ (2004) Interactions between $\beta$-amyloid and central cholinergic neurons: implications for Alzheimer's disease. J Psychiatry Neurosci 29:427-441

113. Moncada S, Bolanos JP (2006) Nitric oxide, cell bioenergetics and neurodegeneration. J Neurochem 97:1676-1689

114. Murphy MP, LeVine H III (2010) Alzheimer's disease and amyloid- $\beta$ peptide. J Alzheimer's Dis 19:311-323

115. Berridge MJ (2011) Calcium signaling and Alzheimer's disease. Neurochem Res 36:1149-1156

116. Sensi SL, Paoletti P, Bush AI, Sekler I (2009) Zinc in the physiology and pathology of the CNS. Nat Rev Neurosci 10:780-792

117. Steinert JR, Chernova T, Forsythe ID (2010) Nitric oxide signaling in brain function, dysfunction, and dementia. Neuroscientist 16:435-452

118. Szutowicz A (2001) Aluminum, NO, and nerve growth factor neurotoxicity in cholinergic neurons. J Neurosci Res 66: $1009-1018$

119. Caricasole A, Copani A, Caruso A, Caraci F, Iacovelli L, Sortino MA, Terstappen GC, Nicoletti F (2003) The Wnt pathway, cell-cycle activation and $\beta$-amyloid: novel therapeutic strategies in Alzheimer's disease? Trends Pharmacol Sci 24:233-238

120. Perez SE, He B, Muhmmad N, Oh KJ, Fahnestock M, Ikonomovic MD, Mufson EJ (2011) Cholinotropic basal forebrain system alterationsin $3 \mathrm{xTg}-\mathrm{AD}$ transgenic mice. Neurobiol Dis 41:338-352

121. Oh JD, Chartisathian K, Chase TN, Butcher LL (2000) Overexpression of neurotrophin receptor p75 contributes to the excitotoxin-induced cholinergic neuronal death in rat basal forebrain. Brain Res 853:174-185

122. Takeda A (2011) Zinc signaling in the hippocampus and its relation to pathogenesis of depression. Mol Neurobiol 44:166-174

123. Frederickson CJ, Maret W, Cuajungco MP (2004) Zinc and excitotoxic brain injury. Neuroscientist 10:18-25

124. Mocchegiani E, Bertoni-Freddari C, Marcellini F, Malavolta M (2005) Brain, aging and neurodegeneration: role of zinc ion availability. Progr Neurobiol 75:367-390

125. Hynd MR, Scott HL, Dodd PR (2004) Glutamate-mediated excitotoxicity and neurodegeneration in Alzheimer's disease. Neurochem Int 45:583-595
126. Supnet C, Bezprozvanny I (2010) Neuronal calcium signaling, mitochondrial dysfunction, and Alzheimer's disease. J Alzheimer's Dis 20:S487-S498

127. Yu JT, Chang RCC, Tan L (2009) Calcium dysregulation in Alzheimer's disease: from mechanisms to therapeutic opportunities. Progr Neurobiol 89:240-255

128. Jhala SS, Hazell AS (2011) Modeling neurodegenerative disease pathophysiology in thiamine deficiency: consequences of impaired oxidative metabolism. Neurochem Int 58:248-260

129. Lai CKJ, DiLorenzo JC, Sheu KFR (1988) Pyruvate dehydrogenase is inhibited in calcium-loaded cerebrocortical mitochondria. Neurochem Res 13:1043-1048

130. Zatta P, Lucchini R, Rensburg SJ, Taylor A (2003) The role of metals in neurodegenerative process: aluminum, manganese and zinc. Brain Res Bull 62:15-28

131. Bizon-Zygmańska D, Jankowska-Kulawy A, Bielarczyk H, Pawełczyk T, Ronowska A, Marszałł M, Szutowicz A (2011) Acetyl-CoA metabolism in amprolium-evoked thiamine pyrophosphate deficits in cholinergic SN56 neuroblastoma cells. Neurochem Int 59:208-216

132. Bossy-Wetzel E, Talantova MV, Lee WD, Scholzke MN, Harrup A, Mathews E, Gotz T, Han J, Ellisman MH, Perkins GA, Lipton SA (2004) Crosstalk between nitric oxide and zinc pathways to neuronal cell death involving mitochondrial dysfunction and p38-activated $\mathrm{K}^{+}$channels. Neuron 41:351-365

133. Doherty GH (2011) Nitric oxide in neurodegeneration: potential benefits of non-steroidal anti-inflammatories. Neurosci Bull 27:366-382

134. Personett DA, Williams K, Baskerville KA, McKinney M (2007) Establishment of cholinergic neuron-like cell lines with differential vulnerability to nitrosative stress. Curr Neurovasc Res 4:75-88

135. Fass U, Panickar K, Personett D, Bryan D, Williams K, Gonzalez J, Sugaya K, McKinney M (2000) Differential vulnerability of primary cultured cholinergic neurons to nitric oxide excess. NeuroReport 11:931-936

136. McKinney M, Williams K, Personett D, Kent C, Bryan D, Gonzalez J, Baskeville K (2004) Pontine cholinergic neurons depend on three neuroprotection systems to resist nitrosative stress. Brain Res 1002:100-109

137. Personett D, Fass U, Panickar K, McKinney M (2000) Retinoic acid-mediated enhancement of the cholinergic/neuronal nitric oxide synthase phenotype of the medial septal SN56 clone establishment of nitric oxide-sensitive proapoptotic state. J Neurochem 74:2412-2424

138. Benilova I, Karran E, De Strooper B (2012) The toxic A $\beta$ oligomer and Alzheimer's disease: an emperor in need of clothes. Nat Neurosci 15:1-9

139. Furst AJ, Rabinovici GD, Rostomian AH, Steed T, Alkalay A, Racine C, Miller BL, Jagust WJ (2012) Cognition, glucose metabolism and amyloid burden in Alzheimer's disease. Neurobiol Aging 33:215-225

140. Butterworth RF (2003) Thiamin deficiency and brain disorders. Nutr Res Rev 16:277-283

141. Exley C, House ER (2011) Aluminium in the human brain. Monatsh Chem 142:357-363

142. Zahr NM, Kimberley L, Harper K, Harper CG (2011) Clinical and pathological features of alcohol-related brain damage. Nature Rev Neurol 7:284-294

143. Ferrer I (2012) Defining Alzheimer as a common age-related neurodegenerative process not inevitably leading to dementia. Progr Neurobiol 97:38-51

144. Klunk WE (2011) Amyloid imaging as a biomarker for cerebral $\beta$-amyloidosis and risk prediction for Alzheimer dementia. Neurobiol Aging 32:S20-S36 
145. Robakis NK (2011) Mechanisms of AD neurodegeneration may be independent of $\mathrm{A} \beta$ and its derivatives. Neurobiol Aging 32:372-379

146. Ishii K, Tamaoka A, Mizusawa H, Shoji SI, Ohtake T, Fraser PE, Takahashi H, Tsui S, Gearing M, Mizutami T, Yamada S et al (1997) A $\beta 1-40$ but not A $\beta 1-42$ levels in cortex correlate with apolipoprotein E $\varepsilon 4$ allele dosage in sporadic Alzheimer's disease. Brain Res 748:250-252

147. Naslund J, Haroutunian V, Mohs R, Davis KI, Greengard P, Buxbaum JD (2000) Correlation between elevated levels of amyloid $\beta$-peptide in the brain and cognitive decline. JAMA 283:1571-1577

148. Hoshi M, Takashima A, Yasutake K, Yoshida N, Ishiguro K, Hoshino T, Imahori K (1997) Nontoxic amyloid $\beta$ peptide 1-42 suppresses acetylcholine synthesis. J Biol Chem 272:2038-2041

149. Perreira C, Santos MS, Oliveira C (1999) Involvement of oxidative stress on the impairment of energy metabolism induced by $\mathrm{A} \beta$ peptides on PC12 cells: protection by antioxidants. Neurobiol Dis 6:209-219

150. Keller JN, Pang Z, Geddes JW, Germeyer A, Waeg G, Mattson MPJ (1997) Impairment of glucose and glutamate transport and induction mitochondrial oxidative stress and dysfunction in synaptosomes by amyloid-beta peptide: role of the lipid peroxidation product 4-hydroxynonenal. J Neurochem 69:273-289

151. Olesen OF, Dago L, Mikkelsen JD (1998) Amyloid $\beta$ neurotoxicity in the cholinergic but not in the serotoninergic phenotype of RN46A cells. Mol Brain Res 57:266-274

152. Resende R, Pereira C, Agostinho P, Vieira AP, Malva JO, Oliveira CR (2007) Susceptibility of hippocampal neurons to A $\beta$ peptide toxicity is associated with perturbation in $\mathrm{Ca}^{2+}$ homeostasis. Brain Res 1143:11-21

153. Harkany TO, Mahony S, Keikser J, Kelly JP, Konya C, Borostyankoi ZA, Gorcs TJ, Zarandi M, Penke B, Leonard BE, Luiten PGM (2001) $\beta$-Amyloid (1-42)-induced cholinergic lesions in rat nucleus basalis bidirectionally modulate serotonergic innervation of the basal forebrain and cerebral cortex. Neurobiol Dis 8:578-667

154. Sarkar P, Narayanan J, Harder DR (2011) Differential effect of amyloid beta on the cytochrome P450 epoxygenase activity in rat brain. Neuroscience 194:241-249

155. Liu T, Perry G, Chan HW, Verdile G, Martins RN, Smith MA, Atwood CS (2004) Amyloid- $\beta$-induced toxicity of primary neurons is dependent upon differentiation-associated increases in tau and cyclin-dependent kinase 5 expression. J Neurochem $88: 554-563$

156. Karuppagounder SS, Xu H, Shi Q, Chen LH, Pedrini S, Pechman D, Baker H, Beal MF, Gandy S, Gibson GE (2009) Thiamine deficiency induces oxidative stress and exacerbates the plaque pathology in Alzheimer's mouse model. Neurobiol Aging 30:1578-1600

157. Zilberter M, Ivanov A, Ziyatdinova S, Mukhatarov M, Malkov A, ALpar A, Tortoriello G, Botting CH, Fulop L, Osypov AA, Pitkanen A, Tanila H, Harkany T, Zilberter Y (2013) Dietary energy substrates reverse early neuronal hyperactivity in a mouse model of Alzheimer's disease. J Neurochem. doi: $10.1111 /$ jnc. 12127

158. Zeng F, Lu JJ, Zhou XF, Wang YJ (2011) Roles of p75NTR in the pathogenesis of Alzheimer's disease: a novel therapeutic target. Biochem Pharmacol 82:1500-1509

159. Walton JR (2009) Brain lesions comprised of aluminum-reach cells that lack microtubules may be associated with cognitive deficit of Alzheimer's disease. NeuroToxicology 30: 1059-1069

160. Kantarci K, Lowe V, Przybelski SA, Senjem MI, Weingand SD, Ivnik RJ, Roberts R, Geda YE, Boeve BF, Knopman DS, Petersen RC, Jack CR Jr (2011) Magentic resonance spectroscopy, $\beta$-amyloid load, and cognition in a population-based sample of cognitively normal older adults. Neurology 77:951-958

161. Crawford JR, Bjorklund NL, Tagliatella G, Gomer RH (2012) Brain serum amyloid $P$ levels are reduced in individuals that lack dementia while having Alzheimer's disease neuropathology. Neurochem Res 37:795-801

162. Blanchard J, Wanka L, Tung YC, Cardenas-Aguayo MC, LaFerla FM, Iqbal K, Grundke-Iqbal I (2010) Pharmacologic reversal of neurogenic and neuroplastic abnormalities and $\operatorname{cog}$ nitive impairments without affecting $A \beta$ and tau pathologies in 3xTg-AD mice. Acta Neuropathol 120:605-621

163. Hamilton LK, Aumont A, Julien C, Vadnais A, Calon F, Fernandes KJL (2010) Widespread deficits in adult neurogenesis precede plaque and tangle formation in the $3 \times \mathrm{Tg}$ mouse model of Alzheimer's disease. Eur J Neurosci 32:905-920

164. Chapman PE, White GL, Jones MW, Cooper-Blacketer D, Marshall VJ, Irizarry M, Younkin L, Good MA, Bliss TVP, Hyman BT, Younkin SG, Hsiao KK (1999) Impaired synaptic plasticity and learning in aged amyloid precursor protein transgenic mice. Nat Neurosci 2:271-276

165. Plaschke K, Kopitz J, Siegelin M, Schliebs R (2010) Insulinresistant brain state after intracerebroventricular dtreptozotocin injection exacerbates Alzheimer-like changes in Tg 2576 AßPPoverexpressing mice. J Alzheimer's Dis 19:691-704

166. Watanabe T, Yamagata N, Takasaki K, Sano K, Hayakawa K, Katsurabayashi S, Egashira N, Mishima K, Iwasaki K, Fujiwara M (2009) Decreased acetylcholine release is correlated to memory impairment in the Tg2576 transgenic mouse model of Alzheimer's disease. Brain Res 1249:222-228

167. Hellstrom-Lindahl E, Viitanen M, Marutle A (2009) Comparison of $A \beta$ levels in the brain of familial and sporadic Alzheimer's disease. Neurochem Int 55:243-252

168. Liu L, Ikonen S, Heikkinen T, Tapiola T, VanGroen T, Tanila H (2002) The effects of long-term treatment with metrifonate, cholinesterase inhibitor, on cholinergic activity, amyloid pathology, and cognitive function in APP and PS1 doubly transgenic mice. Exp Neurol 173:196-204

169. Contestabile A, Fila T, Bartesaghi R, Contestabile A, Ciani E (2006) Choline acetyltransferase activity in brain of Ts65Dn mice, an animal model for Down's syndrome and related neurodegenerative diseases. J Neurochem 97:515-526

170. Ikarashi Y, Hatigaya Y, Tomidokoro Y, Kanai M, Ikeda M, Matsubara E, Kawarabayashi T, Kuribara M, Younkin SG, Maruyama Y, Shoi M (2004) Decreased level of brain acetylcholine and memory disturbance in APPsw mice. Neurobiol Aging 25:483-490

171. Hsiao KK, Borchet DR, Olson K, Johannsdottir R, Kitt C, Yunis W, Xu S, Eckman C, Younkin S, Price D et al (1995) Agerelated CNS disorder and early death in transgenic FVB/N mice overexpressing Alzheimer amyloid precursor proteins. Neuron 15:1203-1218

172. Machova E, Rudajev V, Snyckova H, Koivisto H, Tanila H, Dolezal V (2010) Functional cholinergic damage develops with amyloid accumulation in young adult APPswe/PS1dE9 transgenic mice. Neurobiol Dis 38:27-35

173. Gold M, Hauser RA, Chen MF (1998) Plasma thiamine deficiency associated with Alzheimer's disease but not Parkinson's disease. Met Brain Dis 13:43-53

174. Zhang Q, Yang G, Li W, Fa Z, Sun A, Luo J, Ke ZJ (2011) Thiamine deficiency increases $\beta$-secretase activity and accumulation of $\beta$-amyloid peptides. Neurobiol Aging 32:42-53

175. Humpel C (2011) Chronic mild cerebrovascular dysfunction as a cause for Alzheimer's disease? Exp Gerontol 46:225-232

176. Heinrich CP, Stadler H, Weiser H (1973) The effect of thiamine deficiency on the acetylcoenzyme A and acetylcholine levels in the rat brain. J Neurochem 21:1273-1281 
177. Bubber P, Zj Ke, Gibson GE (2004) Tricarboxylic acid cycle enzymes following thiamine deficiency. Neurochem Int 45: $1021-1028$

178. Zhao N, Zhong C, Wang Y, Zhao Y, Gong N, Zhou G, Xu T, Hong $Z$ (2008) Impaired hippocampal neurogenesis is involved in cognitive dysfunction induced by thiamine deficiency at early pre-pathological lesion stage. Neurobiol Dis 29:176-185

179. Plaitakis A, Hwang EC, Van Woert MH, Szilagyi PI, Berl S (1982) Effect of thiamin deficiency on brain neurotransmitter systems. Ann NY Acad Sci 378:367-381

180. Allen DD, Smith QR (1999) Blood-brain barrier choline transport in the senescent rat. Neurosci Lett 277:198-202

181. Wurtman RJ (1992) Choline metabolism as a basis for selective vulnerability of cholinergic neurons. TINS 15:117-122

182. Yamamura HI, Snyder SH (1973) High affinity transport of choline into synaptosomes of rat brain. J Neurochem 21: 1355-1374

183. Brock M, Nickel AC, Madziar B, Blusztajn JK, Berse B (2007) Differential regulation of the high affinity choline transporter and cholinergic locus by cAMP signaling pathways. Brain Res 1145:1-10
184. Blusztajn JK (1998) Choline, a vital amine. Science 281: 794-795

185. Glenn MJ, Kirby ED, Gibson EM, Wong-Goodrich SJ, Mellot TJ, Blusztajn JK, Williams CL (2008) Age-related declines in exploratory behavior and markers of hippocampal plasticity are attenuated by prenatal choline supplementation in rats. Brain Res 1237:110-123

186. Liapi C, Kyriakaki A, Zarros A, Al-Humadi H, Stolakis V, Gkrouzman E, Anifantaki F, Skandali N, Margaritis M, Tsakiris $S$ (2009) Effect of adult-onset choline deprivation on the activities of acetylcholinesterase $\left(\mathrm{Na}^{+}, \mathrm{K}^{+}\right)$- and $\mathrm{Mg}^{2+}$ ATPase in crucial rat brain regions. Food Chem Toxicol 47:82

187. Pacelli C, Coluccia A, Grattagliano I, Cocco T, Petrosillo G, Paradies G, De Nitto E, Massaro A, Persichella M, Borraci P, Portincasa P, Carratu MR (2010) Dietary choline deprivation impairs rat brain mitochondrial function and behavioral phenotype. J Nutr 40:1072-1079

188. Yao J, Irwin RW, Zhao L, Nilsen J, Hamilton RT, Brinton RD (2009) Mitochondrial bioenergetic deficit precedes Alzheimer's pathology in female mouse model of Alzheimer's disease. Proc Natl Acad Sci USA 106:14670-14675 